\title{
De la represión al patrimonio: vestigios de la violencia de estado en Madrid y Santiago de Chile $^{1}$
}

\author{
From Repression to Heritage: Vestiges of State Violence \\ in Madrid and Santiago, Chile
}

\author{
Maria Chiara Bianchini \\ Instituto de Historia \\ Universidad Católica de Chile
}

\section{RESUMEN}

Este artículo investiga las prácticas sociales que se desarrollan en torno a dos lugares de represión de dos dictaduras del siglo XX: Villa Grimaldi en Santiago de Chile y la Cárcel de Carabanchel en Madrid, España. La conservación y memorialización de "sitios de memoria" es una práctica difundida en el mundo actual. El objetivo de este artículo es analizar críticamente algunos aspectos de la cultura memorial en la que estas prácticas nacen y se despliegan, mostrando la existencia de intercambios y procesos de mímesis entre comunidades de distintos contextos. Adoptando esta perspectiva transnacional, se investigan los actores, los lenguajes, los rituales y los tiempos de los procesos de valorización patrimonial que han afectado a estos sitios en el siglo XXI, evidenciando algunas similitudes y diferencias que indican el desarrollo de una cultura memorial común. Este diálogo sugiere una reflexión sobre algunos aspectos críticos de la cultura de memoria en la que se enmarcan ambos procesos.

Palabras clave: Dictaduras; Derechos Humanos; Cultura de memoria; Patrimonio urbano; Memoriales.

\section{SUMMARY}

This article explores social practices related to two sites of repression both resulting from 20thcentury dictatorships: Villa Grimaldi in Santiago, Chile, and Carabanchel Prison in Madrid, Spain. The conservation and memorialization of "Sites of memory" is a common practice in the contemporary world. The objective here is to analyse critically certain aspects of the memorial culture in which these practices are generated and developed, demonstrating the existence of transnational dialogues and mimetic processes between communities rooted in different contexts. Taking this transnational perspective as its starting point, the article explores the actors, languages, rituals and timing of the heritage valuation processes affecting these two sites in the 21st century, and compares and contrasts similarities and differences, demonstrating the development of a common memorial culture. This dialogue suggests a reflection on various critical aspects of the transnational culture in which these two processes are framed.

Key words: Dictatorships; Human Rights; Memory Culture; Urban Heritage; Memorials.

${ }^{1}$ Una versión preliminar de este artículo ha sido presentada en el XX Congreso de Hispanistas Alemanes, Heidelberg 18-22 de marzo 2015. Agradezco a los participantes de la sección "Transiciones democráticas en la península ibérica y el Cono Sur", por sus comentarios. Esta investigación es parte del proyecto Conicyt-Fondecyt/Post-Doctorado n. 3140430. 


\section{PATRIMONIOS, MEMORIAS, IDENTIDADES}

La cultura contemporánea ha sido definida como un "giro hacia el pasado" o una "era de la conmemoración" (Huyssen 2001; Nora 1992): si los tiempos de la modernidad se estructuraban entorno a horizontes puesto en el futuro, la post-modernidad conlleva un auge de todo lo relacionado con las tradiciones, las genealogías, las memorias, los patrimonios. La ampliación y diversificación potencialmente ad infinitum de los objetos materiales e inmateriales que definimos como "patrimonio" sugiere abandonar una visión de éste como cúmulo de objetos que debemos catalogar y conservar, y desplaza la atención desde los objetos a los sujetos. En esta perspectiva, el patrimonio es una construcción social, vinculada a procesos culturales que podríamos definir de "valoración" o "valorización" del pasado.

Desde hace dos décadas, los Heritage Studies plantean e investigan definiciones de patrimonio centradas en los conceptos de "memoria" — el patrimonio es el "alter ego" u "objetivación" de la memoria (Hartog 2007: 25; Iniesta 2009: 482) — y de identidad. Se teoriza el patrimonio como algo que tiene que ver principalmente con las personas:

El patrimonio es una de las modalidades con que las sociedades se relacionan con su pasado y construyen su identidad alrededor de ello (...) un conjunto diverso de prácticas sociales, procesos y experiencias a través de las cuales las personas invisten las cosas, los lugares y las prácticas de valores y sentimientos, y los reivindican como propiedad colectiva para afirmar la continuidad, la autenticidad y la identidad (...) (Filippucci 2009: 322 y 329)

Vista su relevancia como elemento de las memorias y las identidades, en sociedades marcadas por acontecimientos violentos y conflictivos, el patrimonio puede ser utilizado para distintos fines: para la perpetuación de la dominación y la violencia, para favorecer la "reconciliación" de una sociedad dividida, o como elemento de duelo o reparación para las víctimas de esos eventos, entre otras posibilidades. Las potencialidades y peligros de los usos del patrimonio en sociedades post-conflicto o posttrauma han sido y están siendo abordados por varios estudios (p.e. Ashworth y Tunbridge 1996; Giblin 2013; Viejo Rose 2014), que analizan la producción social del patrimonio como herramienta para la construcción o re-construcción de identidades colectivas después de eventos o procesos de violencia.

Si centramos la atención en el patrimonio material, y en específico en el patrimonio urbano edificado, una de las prácticas asociadas a su producción en sociedades con un pasado reciente de conflicto o represión masiva es la "memorialización" de los acontecimientos de violencia —desapariciones, muertes, atentados terroristas, entre otros-, a través de monumentos, museos y otro tipo de construcciones. Este proceso involucra en algunos casos la identificación, conservación y patrimonialización de los vestigios materiales de edificaciones y lugares en los que se han verificado estos episodios terribles. Algunos lugares de este tipo son el memorial de Auschwitz en Polonia o la Escuela Mecánica de la Armada en Buenos Aires, ejemplos conocidos de una tendencia global que ha producido y sigue produciendo espacios memoriales en muchos países del mundo.

La conservación y memorialización de sitios donde han ocurrido eventos atroces es una expresión de la que Andreas Huyssen ha definido como "globalización" de la 
memoria (2001), que se hace evidente, por ejemplo, en la existencia de redes transnacionales de asociacionismo que conectan memoriales de este tipo, como la International Coalition of Sites of Conscience, integrada por casi doscientos agrupaciones de los cinco continentes ${ }^{2}$.

Este artículo investiga los procesos que se han desarrollado en torno a los vestigios de dos lugares de represión de dos dictaduras del siglo XX — Villa Grimaldi en Santiago de Chile y la cárcel de Carabanchel en Madrid, España-. Ambos lugares han llegado a ser emblemáticos de la represión y la violencia de Estado ejercida por los regímenes pinochetista y franquista, y sus vestigios han sido objeto de procesos recientes de identificación y valorización, que los han investido de significados y trasformado en símbolos.

Para referirse a este tipo de espacios es común que se utilice el término "lugares de memoria". Sin embargo, en la perspectiva de este estudio, este concepto sería inadecuado. Entre otras cosas, el concepto original de lieux de memoire, acuñado por Pierre Nora (1984), remite a procesos relativos principalmente al imaginario de identidades nacionales, y presupone una voluntad conmemorativa y rememorativa del Estado y de las instituciones. El objeto principal del estudio de estos lieux es el Estado-Nación, en el caso específico de Francia, aunque el concepto pueda ser y haya sido adoptado para estudiar fenómenos de otros países (p.e. Winter 2006; Isnenghi 1996).

Este estudio no se refiere a "lugares de memoria" según esta acepción. De hecho, una de las diferencias más notables entre Villa Grimaldi y la Cárcel de Carabanchel es justamente su relación con los Estados y las políticas institucionales. Mientras que la primera es hoy un Monumento Histórico y un memorial que recibe financiaciones públicas, la segunda ha sido destruida y ahora es un solar desierto. Para investigar estos dos lugares, son más adecuados conceptos como patrimonio difícil, conflictivo, disonante, incómodo, negativo. que duele (Ashworth y Tunbridge 1996; Logan and Reeves 2009; Meskell 2002; MacDonald 2009; Uzzell y Ballantyne 2008), que permiten investigar la existencia de múltiples significados y necesidades asociadas al patrimonio, comunidades y diálogos de distintos niveles, intereses diversos, prácticas y costumbres culturales de relación con el pasado que trascienden las voluntades conmemorativas de los Estados y la construcción de lo "nacional".

La patrimonialización de estas herencias difíciles, es decir, su reconocimiento por parte de autoridades con un grado suficiente de legitimidad (Iniesta 2009), es sólo un aspecto de un más amplio proceso cultural de "valoración", en el que diversos actores identifican e interpretan estos vestigios, los invisten de emociones y significados, los reivindican en base a ciertos valores y los transforman en símbolos identitarios (Prats 1997: 22). Se trata de poner el foco, no en la memoria de dos naciones, sino en los procesos sociales y culturales en los que se origina y se desarrolla el valor patrimonial de dos vestigios de la represión: quiénes y cómo descubren estos vestigios, cómo y porqué les otorgan un valor, qué condiciones permiten la legitimación de estas prácticas de memoria en el espacio público, y qué procesos ponen en marcha. Las políticas y voluntades de memoria de las instituciones —que se expresan en las leyes patrimoniales, los traspasos de propiedades, la construcción de monumen-

\footnotetext{
${ }^{2}$ http://www.sitesofconscience.org/members/
} 
tos etc.- , son sólo uno de los factores en juego en estos procesos, relevante sobre todo porque en el mundo contemporáneo los Estados tienen prerrogativa sobre el uso del territorio y la gestión del espacio público.

Los procesos patrimoniales de estos espacios involucran identidades y diálogos de muchos niveles, entre ellas comunidades de memoria transnacionales y locales, y a la vez prácticas que no se limitan a la construcción de monumentos, sino también incluyen otros usos y otras formas de visibilización y difusión. Por esto, la lectura que se hace de estos dos sitios, busca evidenciar no tanto el lieu de memoire, el lugar construido por sucesivas voluntades institucionales como emblema de la memoria nacional, sino tal vez el milieu de memoire, del cual también habló Nora y que ha retomado Aleida Assman al teorizar la memoria cultural (1999: 377): es el medio, el clima, el substrato, en que se desarrolla la vida cultural del pasado en el presente.

El clima de memoria en que adquieren relevancia estos sitios de violencia está condicionado por una cultura y un lenguaje global que algunos caracterizan como "tropos del Holocausto" (Huyssen 2001) o como "paradigma de los derechos humanos" (Jelin 2013). Retomando el concepto teorizado por Halbwachs, este paradigma o tropos sería un "marco social", o "corriente de memoria" (2004), que otorga legitimidad, plausibilidad y lenguajes comunes a iniciativas de memorialización que se desarrollan en contextos distintos, y en referencia a distintos tipos de procesos de violencia ${ }^{3}$. Tanto Huyssen como Jelin han puesto de relieve la necesidad de analizar críticamente las expresiones de este marco global en situaciones concretas. Sugieren investigar por ejemplo, la tendencia de este paradigma por otorgar visibilidad y "poder de palabra" sólo a ciertos actores - legitimados, por ejemplo, para definirse como "Víctimas" - y a ciertas memorias, encubriendo otros conflictos o responsabilidades específicas de cada contexto, o impidiendo la toma de conciencia sobre violencias de más larga historia, que pueden tener su génesis en rasgos culturales más profundos.

Este artículo quiere contribuir a este debate, comparando los procesos de los vestigios de dos espacios de represión y violencia de Estado, que se investigan como dos expresiones locales de una misma práctica global. En esta perspectiva, Villa Grimaldi, que es el primer memorial de estas características en América Latina, y el primer memorial chileno integrado en la red mundial de Sitios de Consciencia es una experiencia pionera, una referencia para posteriores procesos de memorialización de sitios de la represión. En este texto la experiencia de Villa Grimaldi sirve como punto de partida para establecer una comparativa con otro proceso, que es más reciente y que recibe las influencias de aquél en muchas maneras. La comparación es entonces realmente un diálogo, que revela la existencia de intercambios culturales, que constituyen el trasfondo sobre el cual pueden evidenciarse las similitudes y diferencias entre ambos procesos.

\footnotetext{
3 Se utilizan aquí los conceptos de "marcos sociales" de M. Halbwachs y de "corrientes de memoria", que Gerard Namer emplea al interpretar su obra, en referencia a la definición de "memoria social": una memoria que tiene un carácter genérico y difuso; el "ámbito, marco o corriente material o espiritual que engloba la memoria individual"; "un conjunto de nociones o saber vago que reposa en el entorno y en el medio social", "una memoria en y de la sociedad" (citado en Cuesta 2008: 65-67). El sociólogo italiano Paolo Jedlowsky asocia el concepto de memoria social a los de "memoria pública" y de "sentido común" (Jedlowsky 1994). Para una discusión sobre las distintas definiciones de "memoria social", "colectiva" y "cultural", ver, por ejemplo, Baer (2010).
} 


\section{VILLA GRIMALDI}

Villa Grimaldi es un emblema del sistema represivo de la dictadura de Pinochet, en los primeros y más mortíferos años tras el golpe de Estado de 1973. Era una casa residencial, con un jardín arbolado, ubicada en la pre-cordillera al oriente de Santiago, en el barrio periférico de Peñalolén. Desde finales de 1800, la Villa y sus territorios circunstantes pertenecieron a sucesivos dueños privados, que la utilizaron como casa vacacional y luego como restaurante y discoteca. Tras el golpe de 1973, la policía secreta de Pinochet —Dirección de Inteligencia Nacional (DINA) - se hizo con la propiedad $^{4}$. A partir de ese año, y hasta 1978, Villa Grimaldi se convirtió en el Cuartel Terranova, un centro clandestino de detención, tortura y desaparición de personas, por el cual pasaron unos 4500 presos, 236 de los cuales fueron desaparecidos 5 .

Hacia finales de la dictadura, el jefe de la CNI —institución policial sucesora de la DINA - vendió la propiedad a una empresa inmobiliaria vinculada a su familia. En el marco de este traspaso, la villa y las otras instalaciones que se encontraban en el recinto fueron destruidas, con la evidente intención de eliminar las huellas de lo que allí había acontecido. La demolición dejó en el jardín algunos restos de las construcciones anteriores - trozos de madera, azulejos, escombros- que quedaron abandonados en el jardín invadido de arbustos. El lugar pronto se convirtió en objeto de atención por parte de los vecinos del barrio.

\section{DE LA JUSTICIA A LA MEMORIA HISTÓRICA}

Unas imágenes de la actual Corporación Villa Grimaldi, muestran a grupos de personas reunidas en la entrada del recinto abandonado, ya a finales de los años ochenta o principios de los noventa, pintando sus paredes exteriores con consignas por la justicia y contra la impunidad 6 (Fig. 1). Estas acciones — que hoy constituyen el mito de origen del memorial- se enmarcaban en un tejido asociativo local conformado por Comités de Derechos Humanos que operaban en ese distrito, juntas de vecinos, algunas agrupaciones de barrio y parroquias que confluyeron en la Asamblea Permanente de los Derechos Humanos de Peñalolén y La Reina (López 2010). Al igual que en otros barrios populares de Santiago, esta red es parte de un fenómeno de asociacionismo cristiano y popular, que existe en las poblaciones ${ }^{7}$ desde finales

\footnotetext{
${ }^{4}$ Existe un acta de compraventa que demuestra que la casa fue vendida al general del Ejército y jefe de la DINA en junio de 1974. Los motivos del traspaso no son claros y es posible que se haya tratado de una extorsión. De hecho, la DINA habría ocupado el recinto unos meses antes de esta compraventa formal (Aguilar 2005: 12).

5 Veintidós de las víctimas están actualmente calificadas entre los "ejecutados", las demás siguen en calidad de "detenidos desaparecidos". En estos momentos hay varios procesos judiciales abiertos: http://villagrimaldi.cl/victimas/

${ }^{6} \mathrm{http}: / /$ villagrimaldi.cl/imagenes/

7 Se denominan "poblaciones" algunos conjuntos residenciales populares que se ubican principalmente en las zonas periféricas de las principales ciudades de Chile. Muchos de ellos surgieron de la ocupación de terrenos y la auto-construcción por parte de personas sin acceso formal a vivienda, los pobladores. La mayoría de estos conjuntos han sido progresivamente urbanizados y dotados de algunos servicios básicos.
} 


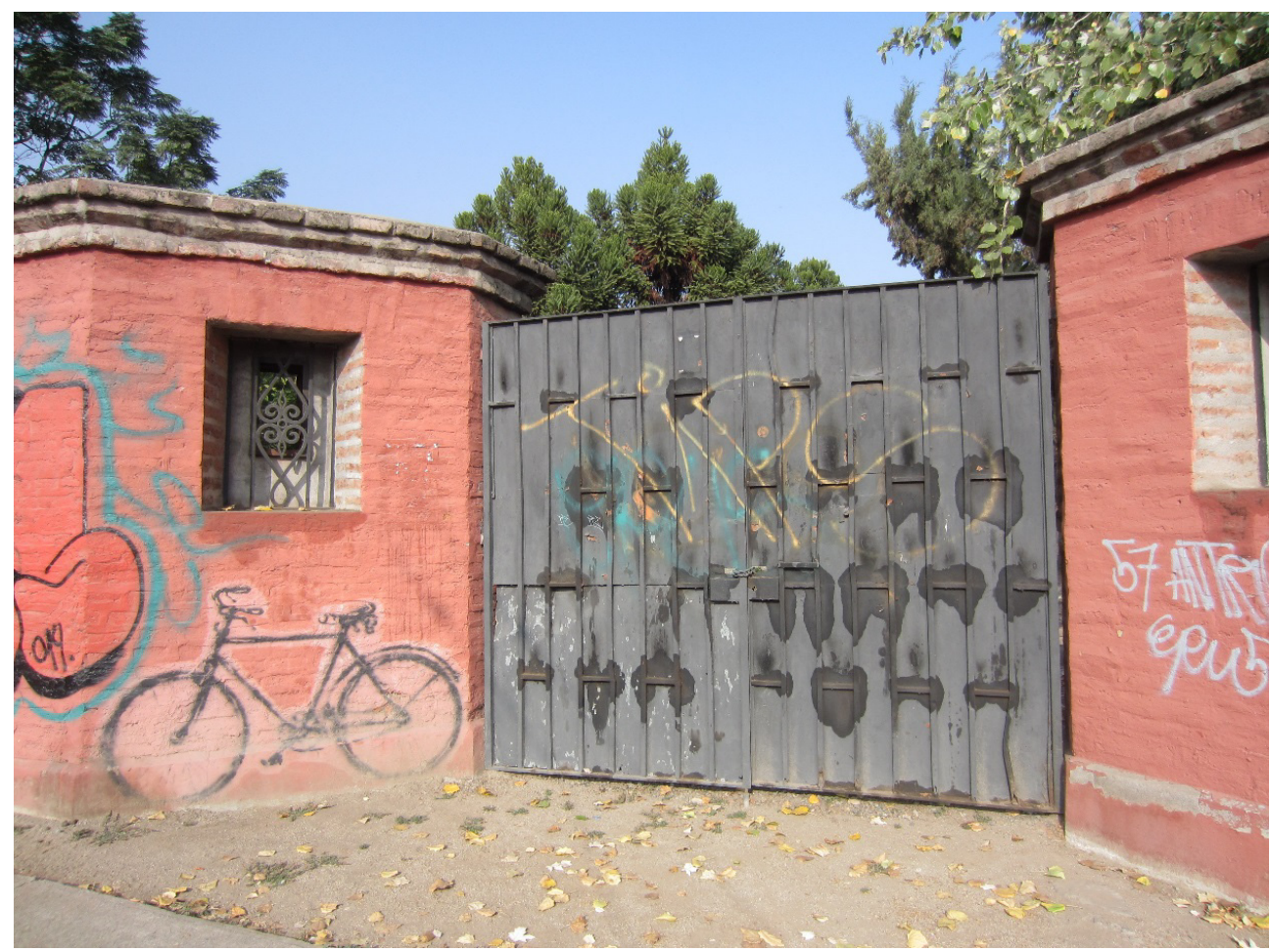

FIG. 1.-Villa Grimaldi: antigua puerta de ingreso. La ságoma de bicicleta pintada al lado izquierdo se inspira en la intervención artística de las "bicicletas de Rosario", difundida en Argentina a partir del 2001 para señalar en el espacio público la ausencia de los detenidos desaparecidos. Fuente: Fotografía de la autora.

de los años setenta, gracias sobre todo a la protección y el trabajo facilitador de distintas instancias de la Iglesia católica y de otras iglesias cristianas (Garcés y Nicholls 2005).

La reivindicación de esta asamblea vecinal se centraba en Villa Grimaldi como documento o evidencia de la represión, y pretendía evitar la completa desaparición de la que amenazaba el proyecto inmobiliario. La consigna inicial era "Abramos Villa Grimaldi", en referencia al carácter clandestino y ocultado de los crímenes que allí se habían cometido. Las manifestaciones de este movimiento inicial tenían un carácter sincrético, entre lo religioso y lo político: romerías y liturgias en torno al recinto abandonado se desarrollaban a la vez que campañas de recogida de firmas e iniciativas de presión hacia las instituciones. En los primeros momentos de la transición, estas acciones pedían la anulación de la venta del terreno, su re-apropiación por parte del Estado y su apertura pública ${ }^{8}$.

\footnotetext{
${ }^{8}$ Ver por ejemplo, Asamblea Permanente de Derechos Humanos del Distrito 24 (Peñalolén y la Reina), "Declaración Pública", 21 de junio de 1991. Archivo Villa Grimaldi: http://www.museovilla grimaldi.info/doc/1_4_1_4.pdf
} 
Aunque en la Asamblea participaban vecinos que habían estado detenidos en el Cuartel Terranova, los ex presos políticos y los familiares de las víctimas no tuvieron un protagonismo destacado en el comienzo de esta reivindicación, sino que su rol se fortaleció sucesivamente, a la vez que se conformaba un marco institucional de políticas de Estado, centrado especialmente en los conceptos de "Víctima" y "reparación". El primer hito fundamental de estas políticas es la creación, en abril de 1990, de la Comisión Nacional de la Verdad y la Reconciliación, que investigó los casos de desaparición y asesinatos entre 1973 y 1990 y que recibió las declaraciones de familiares de detenidos-desaparecidos y ejecutados de todo el país. La publicación del informe de la Comisión en marzo de 1991 es la primera "verdad oficial" sobre el funcionamiento del Cuartel Terranova, que toma forma a través de la investigación de los casos de sus víctimas mortales.

Las "recomendaciones" de la Comisión incluían medidas de "reparación simbólica", que ya preconizan la construcción de un memorial y de un "parque público", "en memoria de las víctimas y los caídos" (Informe de la Comisión por la Verdad y reconciliación, Tomo II, 1996 (1991): 1255). Además de establecer claramente el universo de víctimas que sería objeto de estas políticas simbólicas — que no incluía, por ejemplo, a los sobrevivientes de la detención-, el Informe Rettig también recomendaba que estos memoriales surgiesen como "expresiones consensuales" y no constituyesen "signo de división" sino que contribuyesen a "una mayor unidad e integración social" (Ibidem).

La campaña ciudadana para la conservación de los vestigios de la villa y su apertura al público, se vincula con este proceso institucional desde una etapa muy temprana y se desarrolla en una dinámica de colaboración, negociación y presión hacia las instituciones. En este marco, la consigna de la Asamblea de Peñalolén evoluciona tempranamente desde la apertura de la Villa como evidencia — también jurídica- contra la impunidad, hacia otros objetivos, más cercanos a la conmemoración simbólica que al testimonio. Si en 1991 se reivindicaba el lugar como «un aporte a establecer la verdad y la justicia en nuestro país", dos años más tarde la Asamblea afirmaba que "la situación de impunidad" que se vivía "revela(ba) una vez más la necesidad de construir una medida de reparación en un lugar símbolo como Villa Grimaldi”?.

Las políticas institucionales de reparación, asociadas a la demanda por "abrir» Villa Grimaldi, confluyen en el proyecto de construir un "Parque por la Paz", dedicado a la memoria de los muertos y desaparecidos. El proceso de expropiación del predio y de construcción del Parque no ha sido libre de obstáculos. La epopeya del movimiento ciudadano surgido en torno a este sitio, al igual de los que surgieron luego para "recuperar" a otros lugares de la represión en Chile ${ }^{10}$, consiste justamente en empujar este proceso, presionando desde las bases los equilibrios institucionales de la "transición pactada" (Brunner 1990) o de la "democracia tutelada" (Portales 2000), cuando, entre otras cosas, Pinochet seguía al mando de las Fuerzas Armadas.

\footnotetext{
${ }^{9}$ Asamblea Permanente de Derechos Humanos del Distrito 24 (Peñalolén y la Reina), Declaración Pública, s/f (1992 ca.), Archivo Villa Grimaldi: http://www.museovillagrimaldi.info/doc/ 1_4_1_7.pdf

${ }^{10}$ La expresión "recuperar" es usada comúnmente en el Cono Sur por los grupos ciudadanos movilizados para la memorialización de sitios utilizados para la represión en dictadura.
} 
Tras años de movilizaciones e iniciativas ciudadanas, el predio fue finalmente expropiado en 1994, por un decreto del Ministro de Vivienda y Urbanismo, que había apoyado personalmente la campaña. En 1996, se constituye oficialmente la corporación "Parque por la Paz", conformada por un grupo de unas cincuenta personas - religiosos, expresos políticos, familiares de detenidos desaparecidos, profesionales- con el objetivo explícito de "preservar la memoria histórica de Villa Grimaldi y de otros centros de detención y tortura" y "fomentar y difundir una cultura de los derechos humanos" ${ }^{11}$. Ese mismo año la Corporación presenta el proyecto "Parque por la Paz Villa Grimaldi", y elige el diseño del Parque convocando a un concurso de arquitectura. La construcción del Parque es financiada inicialmente por el Ministerio de Vivienda y se inaugura en 1997, abierto al público bajo custodia y gestión de la Corporación.

\section{De Parque a Museo}

La relación entre demanda ciudadana y políticas institucionales es un factor determinante en el proceso de memorialización de Villa Grimaldi, que influye tanto en la definición de las víctimas a conmemorar, como en los objetivos de la conmemoración. Sin embargo, el memorial no se ha congelado en una representación estática, sino que ha seguido las evoluciones de quienes los gestionan y de la sociedad que lo usa.

Una de las evoluciones más interesantes de Villa Grimaldi en los últimos años, es justamente su progresiva institucionalización en el sistema patrimonial nacional. Mientras en sus primeros años la existencia del Parque por la Paz se desarrolla en la precariedad jurídica y económica, en el siglo XXI va tomando forma un sistema de clasificación que permite incluir este tipo de vestigios en el patrimonio de la Nación. Villa Grimaldi es declarada Monumento Histórico en 2004 y, como tal, está actualmente bajo la jurisdicción del Ministerio de Bienes Nacionales. Al igual que otros centros de detención de la dictadura, Villa Grimaldi está clasificada entre los "monumentos conmemorativos", bajo la categoría de "Memoria y derechos humanos" ${ }^{12}$.

Por otro lado, el Parque por la Paz no sólo ha evolucionado en su estatus legal, sino también en sus formas y contenidos. En 1996, los ex presos y sobrevivientes del Cuartel Terranova tuvieron un papel relevante en el diseño del parque, ya que a través de sus testimonios se reconstruyeron imágenes de lo que había sido el sitio antes de su demolición ${ }^{13}$. Sin embargo, el proyecto elegido no planteó la re-construcción de las instalaciones perdidas, ni el mantenimiento de las ruinas en su estado original, sino que optó por "re-semantizar" el centro de detención en un Parque por la Paz (Violi, 2011), que — conforme a las recomendaciones del Informe Rettig - transmitiese un mensaje de vida y tranquilidad, en contraposición con su pasado de horror y muerte.

\footnotetext{
${ }^{11}$ Corporación Villa Grimaldi, "Acta de Constitución y estatutos", 30 de septiembre de 1996: http:/ /villagrimaldi.cl/wp-content/uploads/2011/07/Acta-de-Constituci\%C3\%B3n-de-la-Corporaci\%C3\%B3n-yEstatutos.pdf

${ }^{12}$ Consejo de Monumentos Nacionales (2014), "Nómina web de Monumentos Nacionales de 1925 al 5 de marzo de 2015": http://www.monumentos.cl/consejo/606/w3-article-22591.html

${ }^{13}$ Corporación Villa Grimaldi (1996), "Proyecto Parque por la Paz": http://www.educacionvilla grimaldi.info/wp-content/uploads/downloads/2011/09/Proyecto-Parque-Por-La-Paz-(1996).pdf
} 
Se construyó un jardín agradable para el encuentro, decorado con "signos universales y neutros" ${ }^{14}$ que promoviesen la reflexión. Se conservaron algunos vestigios y se construyeron algunos elementos conmemorativos: la planta del Parque fue diseñada con la forma de una cruz; las puertas metálicas por las que entraban los coches con los detenidos fueron cerradas para siempre y el acceso impedido con un mosaico en forma de llama, que fue construido con los fragmentos de azulejos que se encontraron entre las ruinas de las construcciones originales (Fig. 2); se instaló en el centro del parque una fuente de agua, también de colores vivos, símbolo de un nuevo bautizo y de purificación (Lazzara, 2007). Villa Grimaldi se transformó así en un parque habilitado para el descanso y el recogimiento, en conmemoración de las víctimas mortales del centro de detención.

El recuerdo concreto de los hechos que habían acontecido en el Cuartel Terranova no encontraba un memorial

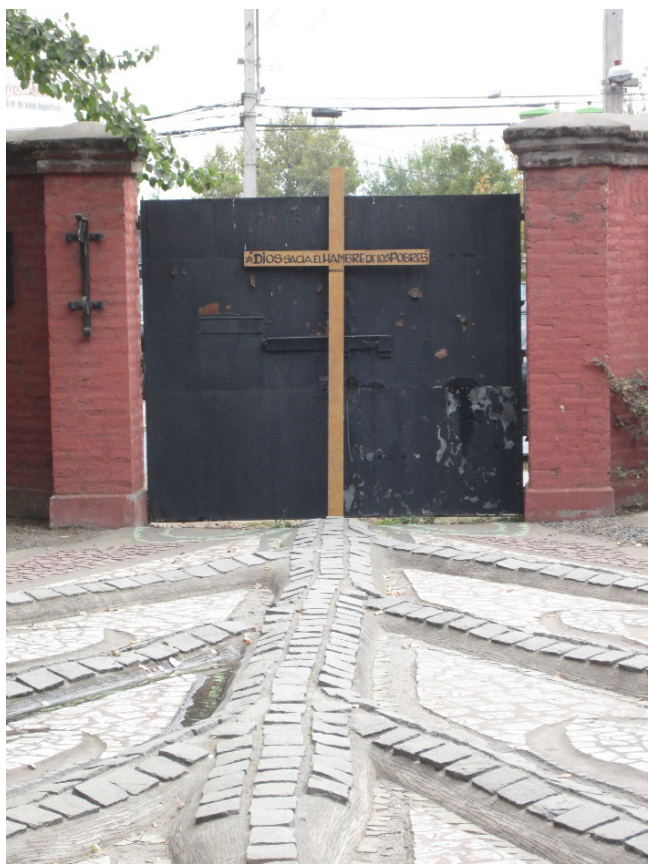

FIG. 2.-Villa Grimaldi. Portón de acceso visto desde el interior. Cerrado permanentemente con un mosaico, y temporalmente con una cruz en ocasión del Vía Crucis Popular de 2014. Fuente: fotografía de la autora. físico en el Parque, sino que, en los primeros años, sólo era transmitido personalmente por algunos ex presos políticos, que guiaban las visitas y relataban sus vivencias mostrando a los visitantes la ubicación de los espacios de tortura y reclusión. Estas visitas funcionaban como una memoria performativa, ya que vehiculaban presencial y oralmente detalles y relatos sobre acontecimientos de violencia, en un lugar cuya estructura visible eludía cualquier referencia que no fuera abstracta y sublimada (Lazzara 2007; Taylor 2010; Violi 2011).

Sin embargo, pocos años después de la inauguración, esta estética de paz y «embellecimiento" (Lazzara 2007: 216) empezó a ser percibida como inadecuada. En 2001, la escritora Nelly Richard planteó una crítica a los elementos de esta memorialización, cuestionando el tipo de relación con el pasado que promovían. Richard hablaba de un "vaciamiento del recuerdo" favorecido por un diseño armónico de paz, que alejaba el recuerdo o la percepción de los acontecimientos terribles de las torturas y los asesinatos, tanto en las formas visuales, como en el tiempo, dando la sensación de algo lejano y ajeno a la vida del presente (Richard 2001).

La crítica de Richard, retomada y desarrollada por varios observadores en los años siguientes, refleja un nuevo clima de memoria, que se abre en Chile hacia finales de los años noventa, favorecido, entre otras cosas, por el procesamiento internacional

\footnotetext{
14 Ibidem.
} 


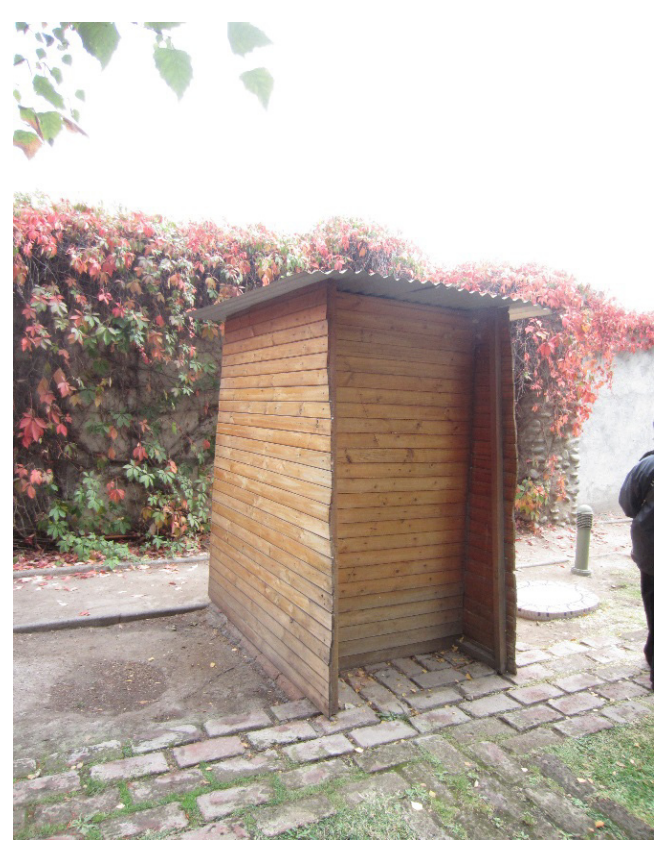

FIG. 3.-Villa Grimaldi, réplica de una de las pequeña celdas de reclusión. Fuente: fotografía de la autora, 2014.

de Pinochet, a partir de octubre de 1998. Este procesamiento —que ya había sido precedido por algunos síntomas de cambio ${ }^{15}$ - contribuyó a trastocarlos equilibrios de la reconciliación oficial, dando legitimidad a nuevos actores y demandas. Entre otras cosas, adquieren relevancia pública y jurídica los testimonios de los expresos políticos y sobrevivientes de lugares como Villa Grimaldi ${ }^{16}$.

En este contexto, el Parque empieza a transformarse paulatinamente, incorporando algunos elementos dirigidos a evocar de forma menos simbólica y más directa los crímenes que en ese lugar se habían cometido. Progresivamente, la estética de la paz va dejando paso a la voluntad de transmitir el recuerdo de aquellos hechos. Hacia 1998 se construye un muro de nombres que recoge las identidades de las víctimas mortales del Cuartel Terranova, y se instala en la entrada del parque una maqueta del sitio original; poco tiempo después aparecen dos réplicas de madera de las pequeñas celdas en las cuales eran mantenidos los prisioneros, y que dan al visitante una idea concreta de su situación de reclusión (Fig 3). En el año 2003 se instala también lo que devendría el principal símbolo del memorial — la "Torre" — réplica de madera de la estructura de un depósito de agua, que había sido usado para el aislamiento y la tortura (Fig. 4).

En el año 2006, la Corporación realiza algunas excavaciones en el predio de la Villa, que sacan a la luz algunos restos de las construcciones originales que habían que-

${ }^{15} \mathrm{El}$ comienzo de un "nuevo clima" se manifiesta por ejemplo en algunas producciones culturales del periodo inmediatamente anterior a la detención del dictador en Londres, como el famoso libro Chile actual. Anatomía de un mito de Tomas Moulian (1997), que denunciaba el blanqueo del pasado sangriento en la cultura de la transición chilena, y que se convirtió rápidamente en un bestseller. También, a principios de 1998, meses antes del arresto internacional de Pinochet, la secretaria del Partido Comunista de Chile había interpuesto ante la justicia chilena la primera querella contra él por un caso de desaparición de persona. Tras el arresto del dictador, las querellas de este tipo se multiplicaron rápidamente.

${ }^{16}$ En coincidencia con el arresto de Pinochet se conforma, por ejemplo, la Agrupación Metropolitana de ex Presos Políticos, que realiza una serie de gestiones para apoyar con sus testimonios la causa abierta en España. La emergencia de un nuevo universo de víctimas se institucionaliza algunos años más tarde, con la publicación de parte del Estado de un nuevo Informe de la Verdad - Informe Valech- centrado, esta vez en los casi cuarenta mil casos de prisión política y tortura entre 1973 y 1990. (Comisión Nacional sobre Prisión política y Tortura, 2004). 
dado sepultados en el proceso de construcción del Parque - los escalones del ingreso a la casa principal y algunos indicios estructurales de una planta subterránea- Las reacciones que siguieron a este descubrimiento son indicativas del cambio que ya preconizaban los nuevos elementos del memorial. Estos vestigios despertaron la "indignación" de los ex presos de la Corporación, que dirigieron ásperas críticas al proyecto original que ellos mismos habían contribuido a construir: "No sabemos qué pasó, si alguien quiso ocultar la historia o fue que les importó más el paisajismo por sobre la historia, pero hoy Villa Grimaldi está hablando y nos quiere decir algo" ${ }^{17}$, afirmó el presidente de la Corporación y ex preso político de la Villa. Evidentemente, los vestigios encontrados tenían en 2006 otro significado respecto al que tenían diez años antes. Los miembros de la Corporación declararon su intención de seguir buscando vestigios enterrados y de rescatarlos como "partes originales

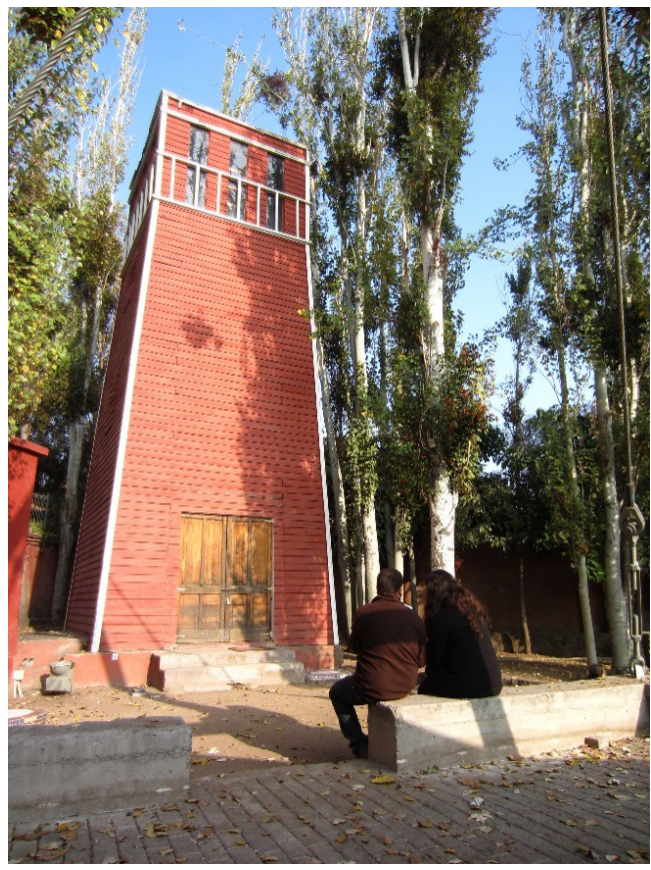

FIG. 4.-Villa Grimaldi, replica de "La Torre", construida hacia 2003. Fuente: fotografía de la autora, 2015. y piezas de esta trágica historia, que deben ser conocidas por todos los chilenos y el mundo" ${ }^{18}$.

Estos cambios indican una evolución en los criterios de valoración de Villa Grimaldi: si la filosofía del Parque por la Paz apuntaba al objetivo de la reconciliación y la conmemoración íntima, la recuperación de los restos de la casa responde a la voluntad de documentar y mostrar públicamente la evidencia de esos hechos. Este criterio estaba presente desde el comienzo de las demandas por la apertura y conservación de este sitio, sin embargo sólo quince años más tarde se dan las condiciones para que los vestigios de la antigua casona empiecen a "hablar". Estas condiciones tienen que ver, por un lado con los objetos mismos, con su pervivencia física y su "capacidad de acción material", por el otro lado, con los cambios en la cultura de quienes los observan y les atribuyen significados. Gracias a la convergencia de ambos aspectos, los vestigios enterrados en 1996 "aparecen" diez años más tarde, y se convierten en el objeto de una nueva "arqueología de la represión" (González-Ruibal y Falquina 2013: 102).

El re-descubrimiento del valor testimonial de Villa Grimaldi produjo, en los años siguientes, nuevas intervenciones en el espacio, que fueron conformando lo que hoy

\footnotetext{
${ }^{17}$ La Nación, 30 de octubre de 2006, "Bajo tierra descubren vestigio de Villa Grimaldi": http:// www.lanacion.cl/noticias/pais/bajo-tierra-descubren-vestigios-de-villa-grimaldi/2006-10-29/204730.html

18 Ibidem.
} 
la Corporación denomina un "Museo de Sitio". En 2007, se instaló una pequeña sala donde se exponen los restos de unos oxidados rieles de tren, que habían sido atados a los cuerpos de personas lanzadas al mar, y recuperados después del año 2000, como pruebas en el proceso contra Pinochet. A partir de 2006 se empezó la construcción de un "Archivo oral" — registro audiovisual y puesta a disposición del público de los testimonios de personas detenidas y torturadas en este lugar-, y un fondo documental —archivo histórico»—, con bibliografía y documentación sobre la represión en dictadura y sobre la historia de Villa Grimaldi. Otro elemento de muy reciente aparición es un cartel que reproduce un organigrama de los funcionarios de la DINA en el cuartel Terranova, que se ha emplazado en la entrada de la "Torre". En la cima del organigrama está Pinochet, con los miembros de la Junta Militar, y siguen hacia abajo militares de distintos grados y un civil, identificados con sus fotos, nombres y apellidos.

Estos nuevos elementos, que conforman ahora un complejo memorial con distintas funciones y espacios, ya no responden a un criterio solo conmemorativo sino también documental. El "Parque" de armonía y reflexión, se ha transformado en el siglo XXI en un monumento-memorial-museo, dirigido a recuperar y exhibir evidencias de los crímenes y abusos perpetrados en este sitio ${ }^{19}$.

Esta evolución en la función del memorial ha sido complementaria con la ampliación y diversificación del universo de víctimas conmemoradas. Por un lado, los cambios que hemos mencionado indican la tendencia de incluir entre las "víctimas" de Villa Grimaldi también a los sobrevivientes. Además del trabajo del archivo testimonial, la Corporación ha promovido recientemente una investigación para establecer un listado exhaustivo de ex presos del centro de detención, y se ha realizado allí un acto conmemorativo, que ha reunido a varios ex detenidos ${ }^{20}$. De estas iniciativas también ha emergido la idea de incluir los nombres de los sobrevivientes en el "muro" de las víctimas, aunque esta propuesta no haya tenido éxito hasta ahora. Por otro lado, a lo largo de la última década, se han incorporado progresivamente unos monumentos que distintos partidos políticos dedican a "sus" víctimas y que, de manera inédita, reivindican su recuerdo a partir de su militancia y pertenencia partidista.

Sin embargo, no sólo los monumentos y los archivos vehiculan los contenidos del memorial y muestran sus transformaciones. En todo este proceso, destaca el rol social de los rituales y las performances que, a través de otras herramientas y lenguajes, también vehiculan identidades y relatos asociados a este sitio. Así como los testimonios de los sobrevivientes circularon también en ausencia de signos físicos — gracias al relato oral de las visitas guiadas - en Villa Grimaldi se desarrollan rituales conmemorativos que complejizan el relato del memorial, por ejemplo incluyendo a su vez a otras "Víctimas" o a ulteriores significados de esta misma palabra.

Es el caso, por ejemplo, del Vía Crucis popular, que se realiza todos los Viernes Santos desde el principio de las movilizaciones en torno a este sitio. Es un ritual híbrido - religioso, conmemorativo y político- que continúa la tradición de los vía crucis populares que se desarrollaban en las poblaciones durante la dictadura. Esta conme-

\footnotetext{
19 http://villagrimaldi.cl/museo/

${ }^{20}$ Corporación Villa Grimaldi, "La historia de Villa Grimaldi se sigue construyendo", 6 de enero de 2015: http://villagrimaldi.cl/noticias/la-historia-de-villa-grimaldi-se-sigue-construyendo/
} 
moración se realiza anualmente desde las primeras romerías en torno a Villa Grimaldi y vehicula la identidad cristiano-popular del movimiento vecinal que dio origen a las primeras movilizaciones para su apertura pública.

Los símbolos cristianos se mezclan aquí con la conmemoración de los desaparecidos, generando imágenes sincréticas como la propia procesión, donde algunas cruces de madera presiden un cortejo que lleva cientos de carteles con los rostros de los desaparecidos (Fig. 5). El recorrido del Vía Crucis repite una parte del trayecto que cumplían los detenidos al ser llevados en coches a la Villa. En alguna ocasión el recorrido incluyó entre sus etapas a un vecino aeródromo desde donde salían los "vuelos" al mar y, más recientemente, al sitio donde se encontraba otro centro de detención y exterminio de la dictadura, hoy desaparecido y transformado en una urbanización residencial ${ }^{21}$.

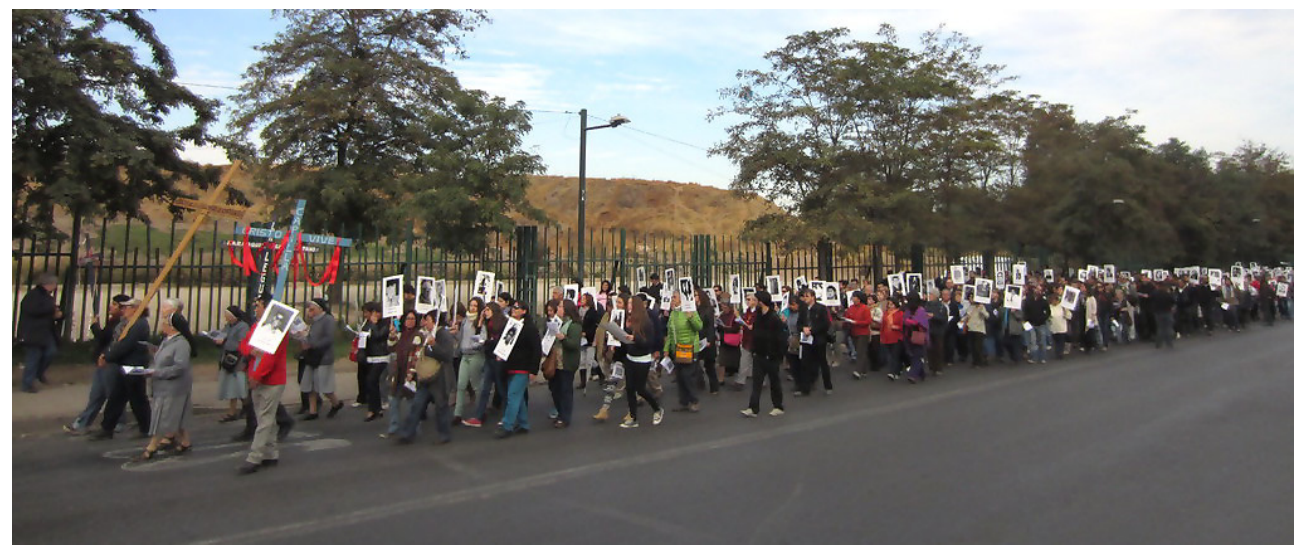

FIG. 5.-Procesión del Vía Crucis Popular hacia Villa Grimaldi en abril de 2014. Fuente: Fotografía de la autora.

La procesión conmemora a las víctimas de estos lugares, pero a la vez las vincula con otras identidades e imaginarios. En particular, las consignas y los símbolos repetidos en el Vía Crucis, hacen referencia a "la causa de los pobres y de los excluidos". Cuando el cortejo se detiene en sus "estaciones", en vez de pronunciar oraciones de la liturgia católica, los participantes repiten consignas y pronuncian discursos sobre las "Víctimas" de hoy, o los nuevos "excluidos": los excluidos del derecho a la educación y la salud, las comunidades indígenas reprimidas en el sur de Chile, los excluidos del derecho al agua y al medio ambiente por los proyectos energéticos y mineros que se desarrollan en los alrededores de Santiago, entre otras consignas. Esta procesión vehicula una identidad de víctimas que es distinta de la que se refleja en los relatos del memorial, pero que se conserva y evoluciona, por ejemplo a través de

\footnotetext{
${ }^{21}$ Se trata del centro de detención denominado "Cuartel Simón Bolivar". Siendo un centro de exterminio, su existencia ha salido a la luz pública sólo en años recientes, gracias a las revelaciones judiciales de un colaborador de la DINA que fueron publicadas posteriormente en una investigación periodística (Rebolledo 2012).
} 
esta performance, que se repite todos los años, y que a la vez renueva su discurso según las necesidades de cada momento. En este ritual los que se consideran los "excluidos de hoy" se identifican con los muertos de la dictadura, y desarrollen una conmemoración, que a la vez sirve para plantear otras denuncias y otras demandas, dirigidas al presente.

\section{LA CÁRCEL DE CARABANCHEL}

Al igual que Villa Grimaldi, la Cárcel de Carabanchel se ha convertido en un símbolo de la represión de la dictadura y, como tal, ha sido objeto recientemente de iniciativas ciudadanas para su conservación y memorialización. También el proceso que ha interesado este sitio tiene una relevancia emblemática, por la centralidad que este centro de detención tenía en el sistema penitenciario nacional y por la visibilidad que adquirió en los medios la campaña para su conservación. Este proceso se pone en marcha diez años después de la inauguración del Parque por la Paz en Chile y, al contrario de éste, no ha llegado a institucionalizarse.

Se trata de edificios muy distintos, que representan distintas "tipologías represivas". La Cárcel de Carabanchel es la "prisión modelo" de Franco construida en Madrid a partir de 1939. No un centro clandestino, sino un enorme panóptico carcelario destinado a representar la modernización e imponencia del sistema penitenciario franquista (fig. 6). Como muchas obras públicas en ese periodo, fue construida utilizando la mano de obra forzosa de los presos políticos, sometidos al régimen de "redención de penas por trabajo" tras la guerra civil (Viejo Rose 2014). Posteriormente acogió presos procedentes de todo el país, siendo un núcleo principal de la espesa red de centros de reclusión que convirtieron a "toda España" en una cárcel (Serrano y Serrano 2003).

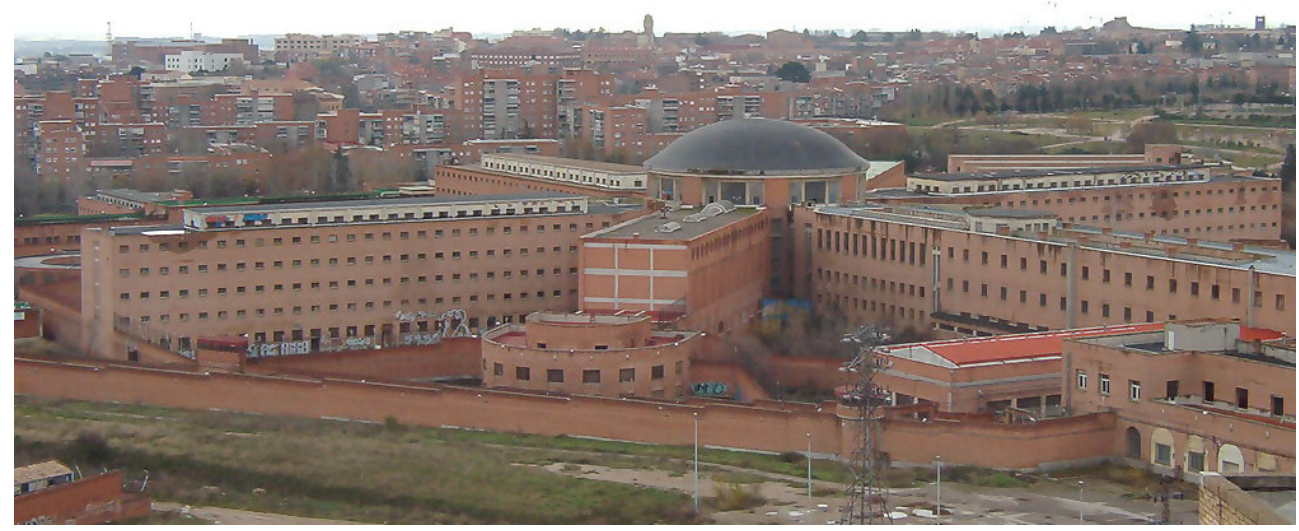

Fig. 6.-Panóptico de la Cárcel de Carabanchel, 2003.

Fuente: commons.wikimedia.org (CC-BY-SA 2.0). 
Carabanchel se mantuvo en función hasta veinte años después del comienzo de la transición y acogió a miles de personas, detenidas por distintas razones: además de dirigentes políticos y sindicales, el franquismo encerró aquí, por ejemplo, a homosexuales detenidos bajo la ley de "vagos y maleantes", a militantes de grupos de izquierda e independentistas, así como muchos otros tipos de presos clasificados como "Comunes". Cuando se cerró en 1998, quedaban en sus celdas unos pocos miles de detenidos, vinculados principalmente con la micro-delincuencia y muchos de los cuales estaban enfermos de SIDA.

Por un lado, las diferencias entre la historia de Villa Grimaldi y la de Carabanchel en los primeros años tras el fin de ambas dictaduras son indicativas del distinto "clima" de memoria en que empezaron ambas transiciones. Mientras que alrededor del centro de detención chileno, al principio de la transición se movilizaron una serie de individuos y colectivos organizados ya durante la dictadura bajo la insignia de los "derechos humanos", la consigna anti-franquista del comienzo de la transición era "amnistía". Una de las imágenes más recordadas de esos años corresponde con la liberación de la Cárcel de Carabanchel de algunos destacados dirigentes políticos y sindicales, que salieron en libertad tras el primer decreto de amnistía de 1976. En esos momentos, la ley fue celebrada por la opinión anti-franquista como una victoria.

Por otro lado, al igual que en el caso de Villa Grimaldi, la historia de Carabanchel en los primeros años de la transición, evidencia los límites difusos que marcan el cambio de uno a otro régimen. Después de la amnistía, las movilizaciones en las cárceles continuaron, protagonizadas por miles de presos que demandaban la liberación también de los que habían quedado excluidos del indulto, y que se autodefinían como "presos sociales". El motín más famoso de este movimiento se realizó en Carabanchel a partir del 18 de julio de 1977, coincidiendo con el aniversario del golpe de Estado, que había dado inicio a la guerra civil en 1936. En los días siguientes cientos de presos subieron al tejado de la cárcel pidiendo amnistía y denunciando sus condiciones de reclusión y los abusos de los que eran víctimas. Estas iniciativas fueron brutalmente reprimidas (Lorenzo Rubio 2013). Entre otras cosas, en 1978 un detenido resultó muerto a causa de las torturas.

\section{DEL ABANDONO A LA MEMORIA HISTÓRICA}

Tras el cese de sus funciones, la Cárcel estuvo bajo la amenaza de ser destruida y sus terrenos vendidos en el mercado inmobiliario. También en este caso la demanda por la conservación del edificio se pone en marcha frente a la posibilidad de su desaparición. Desde principios de los años noventa, una reforma de instituciones penitenciarias preveía su cierre, así que la Cárcel se fue vaciando progresivamente, aunque la venta de los terrenos no logró concretarse, debido a un conflicto de propiedad entre distintas instituciones: los Ministerios de Defensa y del Interior, por un lado, y las autoridades regionales de la Comunidad y del Ayuntamiento de Madrid por otro. La demanda por la conservación de la Cárcel tiene su génesis en unas movilizaciones vecinales que surgieron en este contexto y que desde mediados de los años noventa, se opusieron al proceso de venta de los terrenos, realizando campañas de recogida de firmas y distintos tipos de manifestaciones (Ortiz 2013). 
Estas movilizaciones —organizadas principalmente por las Asociaciones de Vecinos de los distritos aledaños al predio-, reclamaban al Estado que los terrenos de la Cárcel fueran utilizados para la construcción de servicios sociales necesarios en el barrio, entre ellos sobre todo un hospital. No repararon inicialmente en la idea de conservar la Cárcel, sino que al contrario, por lo general estos vecinos deseaban su destrucción $^{22}$. Para ellos el edificio no tenía un valor "patrimonial", sino que era un símbolo negativo, que recordaba el franquismo, y además contribuía al estigma de delincuencia y marginalidad que pesaba sobre el barrio (García García 2013).

Inmediatamente después del abandono, existieron algunas iniciativas que se referían al valor histórico de la cárcel abandonada —una exposición y unas visitas guiadas que fueron organizadas por la Dirección de Instituciones Penitenciarias en 1998, y el concierto de un famoso artista nacional en 1999-, sin embargo, estas iniciativas no llevaban incluida la idea de conservar el edificio, ni tampoco tuvieron ulteriores consecuencias. La cárcel quedó abandonada. Rápidamente las instalaciones fueron habitadas por personas sin techo y los materiales del edificio fueron objeto de un espontáneo proceso de reciclaje que fue transformando el edificio en una ruina (Ortiz 2013).

Los vecinos movilizados en favor del hospital no quedaban indiferentes al tremendo poder evocador de estas ruinas, pero sólo hacia el año 2008 aparece en su discurso una nueva idea de "memoria", asociada al edificio en cuanto emblema de la represión franquista. Como en el caso de Villa Grimaldi, este cambio en los lenguajes y las demandas se enmarca en un proceso cultural más amplio, que favorece la aparición de nuevas ideas.

El clima cultural, en el cual se origina una demanda patrimonial relativa a la Cárcel de Carabanchel es la "irrupción de memoria" ${ }^{23}$ con que se abre el siglo XXI en España, cuyo fenómeno más destacado es la aparición mediática de las fosas comunes de la guerra civil a partir del año 2000 (Ferrándiz 2014). Este proceso incluye la conformación y ramificación de un inédito asociacionismo por la "memoria histórica", que permite encuentros e intercambios, y se nutre de lenguajes y conceptos que también proceden de otros países ${ }^{24}$. Esta irrupción también incluye algunas iniciativas institucionales, que culminan en 2007 en la aprobación de la llamada "Ley de memoria Histórica", cuyo objetivo explícito era establecer medidas "en favor de quienes padecieron persecución o violencia durante la guerra civil y la dictadura". Entre otras cosas, esta Ley estableció la eliminación de los monumentos y símbolos de ideología franquista de los edificios públicos, y la realización de un censo de eedificaciones y obras realizadas mediante trabajos forzosos ${ }^{25}$, aunque no estableciera pautas para la

\footnotetext{
${ }^{22}$ Entrevista Antonio Castillo, Asociación de Vecinos de Aluche, Madrid 30.03.2015

${ }^{23}$ Esta expresión fue utilizada por Wilde (1999) para describir el fenómeno cultural que provocó en la sociedad chilena el arresto de Pinochet en Londres en 1998.

${ }^{24}$ F. Ferrándiz ha puesto en evidencia el traslado del concepto y la iconografía de los desaparecidos desde el Cono Sur a España. En el ámbito de la conservación de espacios represivos y la eliminación de los símbolos urbanos franquistas - como en el caso de la Cárcel de Carabanchel- los memoriales argentinos y chilenos son referencias frecuentes, cuyo ejemplo se invoca para legitimar estas demandas.

${ }^{25}$ Artículos 15,16 y 17. "LEY 52/2007, de 26 de diciembre, por la que se reconocen y amplían derechos y se establecen medidas en favor de quienes padecieron persecución o violencia durante la guerra civil y la dictaduraw: http://www.boe.es/boe/dias/2007/12/27/pdfs/A53410-53416.pdf
} 
conservación o patrimonialización de estas obras, ni de los sitios utilizados para la represión durante la dictadura ${ }^{26}$.

El cambio cultural de la "irrupción de la memoria", se hace presente en las iniciativas sobre Carabanchel a partir de una exposición fotográfica que los vecinos organizaron en 2007, cuyo título —Cárcel de Carabanchel: de la represión al olvido- ya reflejaba un cambio de percepciones. La idea de conservar los vestigios de la Cárcel surge en torno a esta exposición, favorecida por la convergencia de las iniciativas vecinales con el trabajo de un grupo de antropólogos que se habían interesado y acercado a este sitio $^{27}$. Gracias al encuentro y la colaboración con estos investigadores, los vecinos "se hicieron conscientes" o "se dieron cuenta", de que la Cárcel, o por lo menos una parte de ella, debía ser conservada, en nombre de la "memoria histórica" 28.

De estas convergencias nace el "Proyecto Integral" para los terrenos de la Cárcel de Carabanchel, que fue aprobado en 2008 por las asociaciones de vecinos. Un proyecto detallado para el futuro uso de los terrenos que incluía, además de un hospital, una biblioteca y una residencia para ancianos, también un "Centro por la Paz y la Memoria", con una exposición permanente sobre la represión y la resistencia anti-franquista y un centro de documentación que estaría dedicado a los "derechos humanos", aunque su contenido concreto no se detallara en esa etapa. El centro por la memoria se ubicaría en la cúpula central del panóptico, el espacio considerado como "más emblemático", y que debía conservarse ${ }^{29}$.

En esos momentos ya existían algunos precedentes de patrimonialización de espacios represivos en España. Sin embargo, al no existir una política de alcance estatal relativa a este tipo de patrimonios, el éxito institucional de estas iniciativas de conservación dependió en cada caso de la voluntad y de la orientación política de los distintos gobiernos autonómicos. Entre otras cosas, los procesos que interesan a estos sitios indican diferencias en el tratamiento institucional del pasado franquista en las políticas simbólicas de las distintas administraciones regionales presentes en España ${ }^{30}$. Debido a su situación específica en este contexto, la Cárcel de Carabanchel

${ }^{26}$ El único monumento que la ley aborda de manera específica es el Valle de los Caídos, en la Comunidad de Madrid. Consecuente a lo establecido por esta ley, se conformó una comisión gubernamental de expertos para la transformación de este monumento. Sin embargo, la propuesta de la comisión ha quedado en letra muerta tras el cambio de gobierno en noviembre de 2011. El informe de la Comisión puede verse en: http://digital.csic.es/handle/10261/85710

${ }^{27}$ El primer producto de este proyecto de investigación fue un video-documental titulado "La Cárcel de Carabanchel: un modelo de espacio para la represión", CSIC-FECYT, (DVD), 2007. Esta investigación también se vinculó parte de un proyecto académico internacional sobre políticas patrimoniales en sociedades post-conflicto, "Cultural Heritage and the Reconstruction of Identities after conflicts" 2008-2012: http://www.cric.arch.cam.ac.uk/

28 Antonio Castillo, entrevista citada.

29 Coordinadora vecinal de Latina y Asociaciones de Vecinos de Carabanchel Alto y Parque Eugenia de Montijo , "Proyecto Integral para los terrenos de la Cárcel de Carabanchel", 2008. Un resumen del proyecto puede verse en: http://www.carabanchelalto.org/aavv/spip.php?article360

${ }^{30}$ Por ejemplo la Isla de San Simón fue objeto de un proyecto de memorialización de la Xunta de Galicia en 2005, aunque finalmente derivó en su transformación en un centro cultural sin más referencias a su historia de represión durante el franquismo (Sánchez-Carretero 2013). También se habían desarrollado proyectos de sitios memoriales en Euskadi (el Museo de la Paz de Guernika, inaugurado en su perfil actual en 2003) y en Catalunya (el Memorial Democrátic fue creado en 2008). Un ejemplo de patrimonialización a partir de un movimiento ciudadano es el Canal 
no sólo no ha sido transformada en monumento, sino que todo lo contrario. En 2008, las instituciones competentes llegaron a un acuerdo sobre la irresuelta cuestión de la propiedad de los terrenos y firmaron un proyecto que preveía la demolición del panóptico carcelario.

A partir de ese momento, empeñada en evitar el derribo, la Plataforma por un Centro por la Paz se puso en contacto con distintas instituciones, solicitando - $-\mathrm{y}$ en algunos casos obteniendo- apoyos. A lo largo de algunos meses, las manifestaciones y las gestiones políticas de este grupo se incrementaron y diversificaron en número y participación, y se hicieron presentes en los medios de comunicación (Ortiz 2013). La conservación de la cárcel se convirtió así en una campaña ciudadana.

Sin embargo, mientras estas manifestaciones y gestiones se estaban realizando, en octubre de 2008, una empresa contratada por el Ayuntamiento de Madrid empezó la demolición. Los trabajos comenzaron de forma sorpresiva y nocturna, y las maquinarias se dirigieron directamente a la cúpula central del panóptico, que fue el primer elemento en ser destruido. En los días siguientes, algunos medios de comunicación mostraron imágenes de la demolición de la Cárcel, que atestiguan el acto de violencia de este derribo, retratando a los vecinos frente a la cúpula semi-destruida, con una pancarta que reza "Salvemos una parte de la Cárcel de Carabanchel para la memoria". Al igual que Villa Grimaldi, la Cárcel de Carabanchel también fue destruida, aunque en este caso no lo fue por la voluntad de ocultación de un gobierno dictatorial, sino por un acuerdo entre instituciones democráticas.

\section{FRAGMENTOS Y HERENCIAS INTANGIBLES}

La demolición duró algunas semanas y luego se sucedió más silenciosamente en distintos momentos. En un principio quedaron algunas instalaciones y parte del muro del recinto con algunas torretas de vigilancia. Luego se fueron destruyendo también estos elementos. Los escombros de la cárcel fueron molidos y depositados sobre el suelo del recinto, en un gesto que recuerda las metáforas de "pasado bajo tierra" (Ferrándiz 2014) o de palabras "enterradas" (Valverde 2013), que han sido usadas para referirse a la cultura de memoria en la dictadura y la transición española. Actualmente, en el sitio sólo queda una puerta semi-derruida, un extraño vestigio dejado en pie sin explicación aparente (Fig. 7). Por lo demás, aún no se ha concretado ningún proyecto de construcción en estos terrenos, así que el solar sigue desierto, como un nolugar o un fantasma difícil de gestionar.

Sin embargo, el simbolismo de la Cárcel de Carabanchel no ha desaparecido con la destrucción del edificio. Por un lado, es interesante la vida cultural que han tenido algunos de sus fragmentos materiales. Es el caso por ejemplo de un ladrillo del edificio original, que fue recogido en el proceso de demolición y enviado a la familia de un destacado dirigente sindical y ex preso de Carabanchel, como homenaje de reco-

de los Presos de Sevilla, una obra hidráulica construida por el franquismo con mano de obra de presos, reivindicada insistentemente por los movimientos locales para la memoria histórica a lo largo de la última década, y finalmente declarada "lugar de memoria" por la Junta de Andalucía en 2013. 


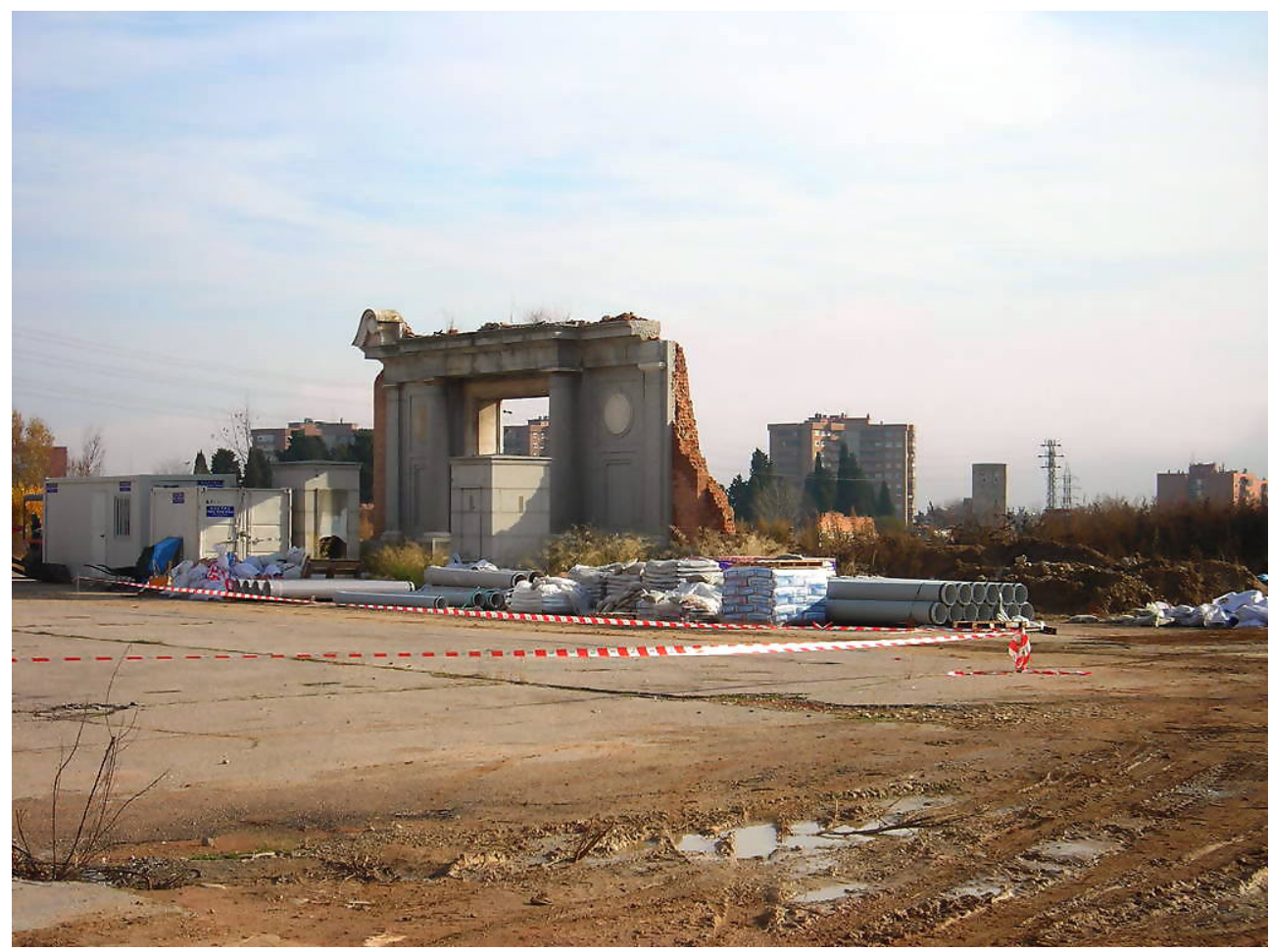

FIG. 7.-Vestigio de la puerta de ingreso de la Cárcel de Carabanchel después del derribo del edificio. Fuente: fotografía de la autora, 2011.

nocimiento de parte de la Dirección de Instituciones Penitenciarias. Recientemente, este ladrillo ha sido el objeto central de una exposición artística que construye una reflexión sobre los problemas del "recuerdo histórico", alrededor de la historia de este fragmento y de los conflictos que lo rodean ${ }^{31}$. El recorrido artístico de este ladrillo atestigua la pervivencia de un valor patrimonial asociado a la cárcel, aunque el edificio haya desaparecido.

Por otro lado, una vez cumplido el derribo, el movimiento ciudadano surgido en torno a Carabanchel ha seguido su curso por distintos derroteros. Las experiencias han generado nuevos aprendizajes y vínculos, que constituyen herencias intangibles de la Cárcel desaparecida. Como afirma uno de los vecinos más comprometidos con esta causa: "el patrimonio que queda de Carabanchel, somos las personas” ${ }^{32}$. De manera parecida a lo que aconteció en Villa Grimaldi, alrededor de la campaña por la conservación de la Cárcel se ha conformado una comunidad, que no se extingue con la desaparición del edificio, sino que se transforma y, en cierta medida, se puede decir

\footnotetext{
${ }^{31}$ Sobre la historia de este ladrillo y de la exposición artística: http://salvemoscarabanchel. blogspot.com.es/2015/03/esto-si-es-un-ladrillo.html.

32 Antonio Castillo, entrevista citada.
} 
incluso que toma impulso. Por ejemplo, esta comunidad sigue existiendo virtualmente, a través de un blog y otras redes sociales, y participa en otras agrupaciones ciudadanas para la preservación del patrimonio en Madrid $^{33}$. Por iniciativa de este grupo, la cárcel — materialmente inexistente- ha llegado también a ser miembro de la Coalición Internacional de Sitios de Conciencia.

También en este caso, al igual que en Villa Grimaldi, entre las prácticas de esta comunidad destaca la relevancia de las performances. Los vecinos siguen realizando visitas guiadas al solar, en las que muestran fotografías del sitio original y cuentan relatos sobre la cárcel y sobre las movilizaciones para su conservación. También se realizan periódicamente rituales conmemorativos, que constituyen momentos privilegiados para la agregación y la transmisión de testimonios y discursos, en ausencia de monumentos y archivos. La fecha más importante de estas manifestaciones es el 23 de octubre, cuando se conmemora el aniversario del derribo de la Cárcel en 2008, que se ha transformado en una ocasión de denuncia de las políticas de olvido del estado español.

En las manifestaciones organizadas alrededor de este aniversario participan anualmente algunas centenas de personas, entre activistas, vecinos y ex presos políticos. Año tras año se han instalado en distintos puntos del enorme solar donde estaba la Cárcel algunos símbolos memoriales: un mural - hecho en cartón e instalado en las vallas externas del recinto- que recoge los nombres de algunos cientos de presos políticos que pasaron por este presidio; una miniatura del panóptico hecha de cemento y ladrillo, que fue instalada en una esquina; un "jardín de la memoria" — conformado por árboles y flores que fueron plantado simbólicamente por algunos ex presos políticos en 2011 (Figs. 8 y 9).

Los elementos de esta memorialización y de las actividades conmemorativas que aquí se realizan recuerdan algunos de los símbolos que encontramos en Villa Grimaldi: los nombres, las fotografías, el jardín in memoriam. Sin embargo, al contrario de lo que pasa en el memorial chileno, desde su primera inauguración, el memorial de Carabanchel ha tenido que ser reparado y reconstruido varias veces, debido sobre todo a los ataques de los que es objeto, justamente porque no nace de un consenso público ni de una política estatal.

Al igual que en Villa Grimaldi, estas iniciativas conmemoran a un universo determinado de víctimas, que se convierten en los principales referentes y destinatarios de la memoria histórica que se reivindica en este lugar. Las víctimas "de la represión y la violencia" conmemoradas en Carabanchel son principalmente los presos políticos, definidos como tales por el régimen que los encarceló, y que en los años sesenta y setenta ocupaban la sexta galería del panóptico penitenciario. Es interesante notar que los presos que ocupaban las restantes siete galerías durante y después del franquismo han estado mayoritariamente ausentes de estas reivindicaciones. Las figuras más emblemáticas de la campaña en torno a Carabanchel son principalmente dirigentes políticos y sindicales que salieron de la cárcel con los decretos de Amnistía. Ellos son las víctimas que adquieren legitimidad para hablar también en nombre de los represaliados del primer franquismo.

En este caso, las víctimas en nombre de las cuales se realizaron las primeras manifestaciones eran representadas principalmente por ex presos vinculados en esos años con

\footnotetext{
${ }^{33}$ La página web de esta plataforma ciudadana es: salvemoscarabanchel.blogspot.com.es
} 


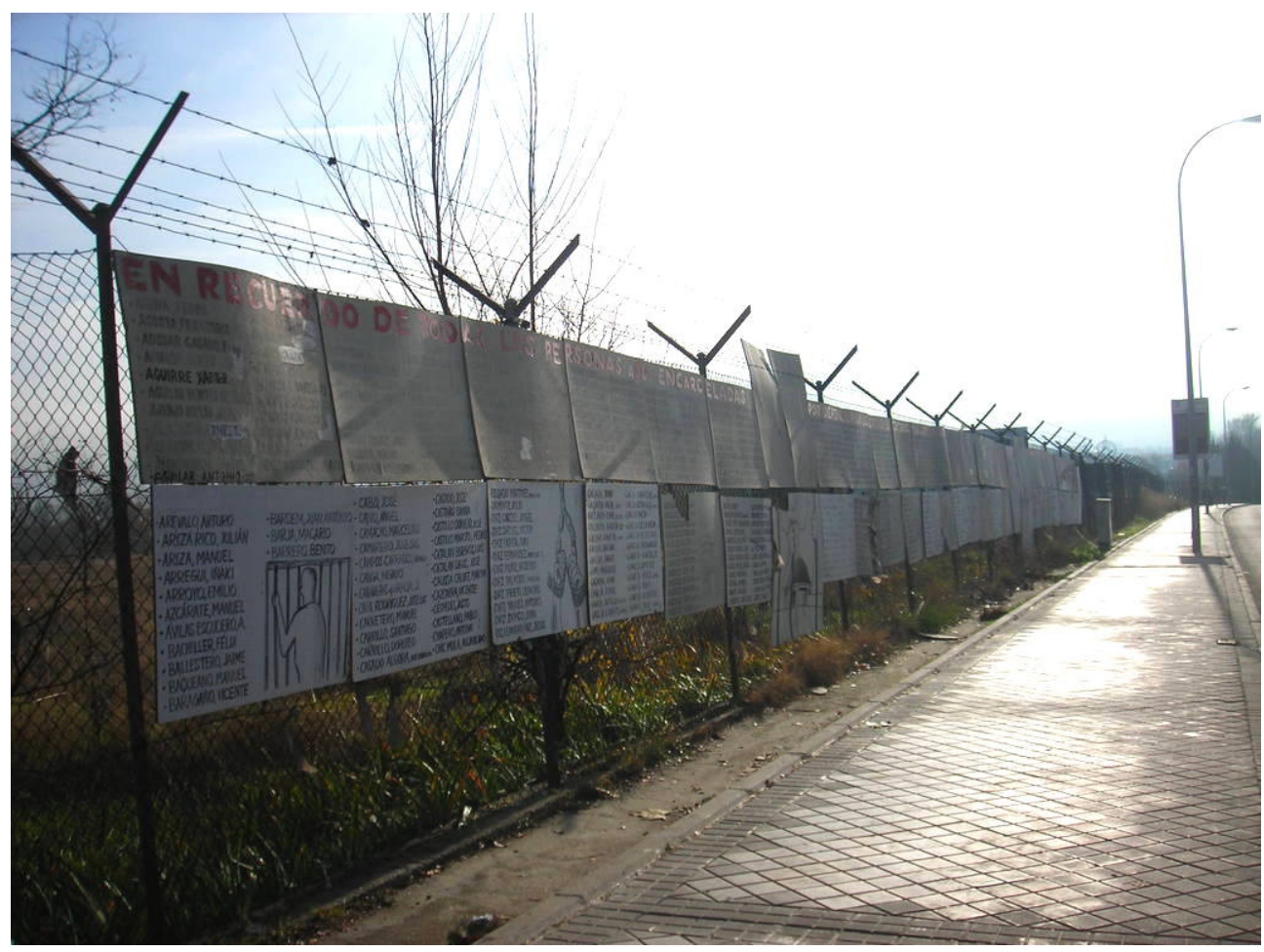

FIG. 8.- Memorial de nombres en la valla externa del solar de la Cárcel. Fuente: fotografía de la autora, 2011.

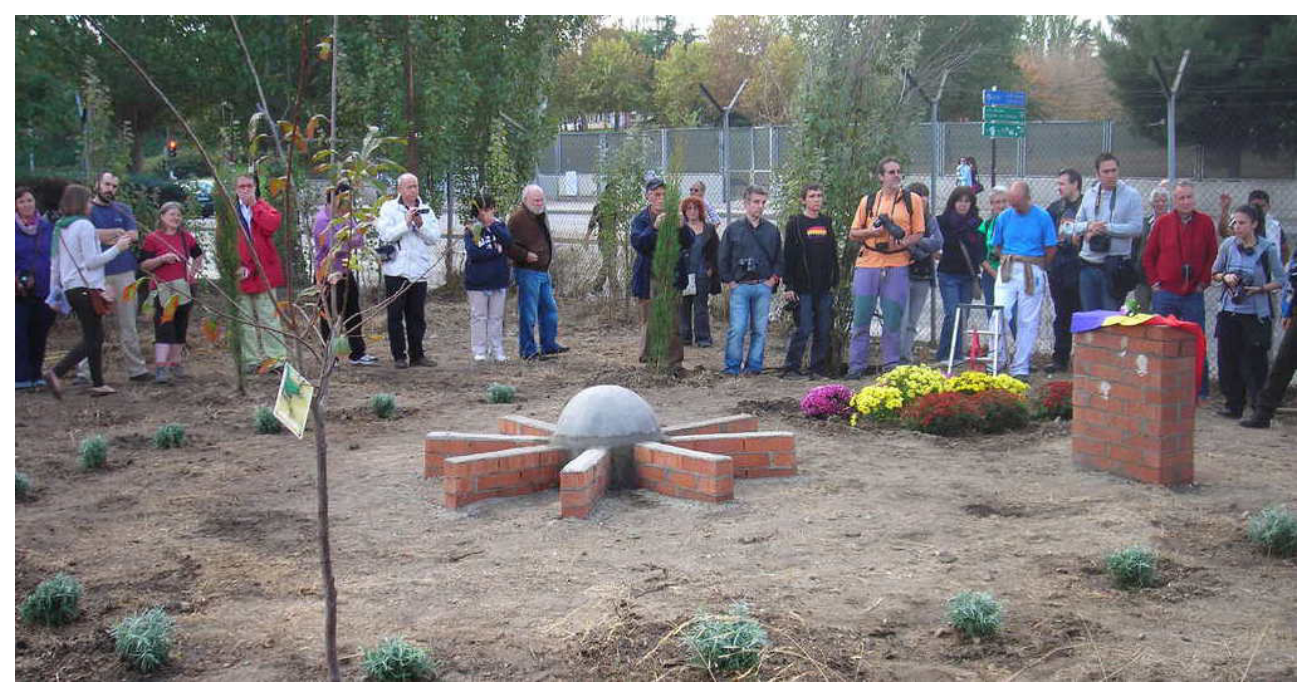

FIG. 9.- Inauguración del "Jardín de la memoria", con una reproducción en miniatura del panóptico y una estela conmemorativa. Octubre, 2011. Fuente: fotografía de la autora. 
el Partido Comunista y con la organización Frente Revolucionario Antifranquista y Patriótico (FRAP), vinculada a éste. La primera gran conmemoración que se realizó en las ruinas de la Cárcel en 2007 coincidió con el 27 de septiembre, aniversario del fusilamiento de los últimos tres presos de Carabanchel en 1975, que eran militantes del FRAP. Se descolgaron de las paredes de la cárcel unos lienzos con las fotografías de estos tres militantes, que fueron conmemorados en primer lugar por algunos de sus compañeros de militancia y detención. No aparecían aquí, por ejemplo, los rostros de los otros dos fusilados en ese mismo día — que no habían salido de la cárcel de Carabanchel, sino de la de Burgos y Barcelona- y que eran militantes de ETA. Tampoco aparecían en estas conmemoraciones los presos sociales de los primeros años de la transición, ni los de la última etapa de funcionamiento de la penitenciaria. Al igual que en Villa Grimaldi, estas selecciones - conscientes o no-, contribuyeron a la construcción de la identidad del movimiento ciudadano por la conservación de Carabanchel: conforman el contenido de sus memorias y caracterizan sus reivindicaciones patrimoniales.

Sin embargo, al igual que en Villa Grimaldi, la demanda por la conservación de la Cárcel también ha evolucionado en los últimos años. Por un lado, ha contribuido a la creación y fortalecimiento de nuevas redes ciudadanas, que actúan más allá del ámbito estrictamente patrimonial. Es el caso de la asociación de expresos denominada $\mathrm{La}$ Comuna que está conformada principalmente por antiguos militantes comunistas. La Comuna recupera el nombre de los colectivos auto-organizados por los presos en las cárceles franquistas y toma impulso en torno a las reivindicaciones por Carabanchel. Entre otras cosas, desde el año 2010, La Comuna ha apoyado activamente las investigaciones y diligencias de la justicia argentina relativas a los crímenes de lesa humanidad del franquismo. La "querella argentina" - la primera iniciativa legal transnacional dirigida al Estado Español por los crímenes del franquismo- se desarrolla en el marco de la justicia internacional humanitaria y es uno de los ejemplos más reciente de los "diálogos" que caracterizan el clima de la memoria en el área iberoamericana ${ }^{34}$.

La derivación de la demanda por la conservación de la Cárcel en esta iniciativa jurídica transnacional sugiere un punto de comparación entre este proceso y el de Villa Grimaldi. Allí las iniciativas de conservación del sitio se motivaron inicialmente a partir de una demanda de justicia y contra la impunidad. Sin embargo luego se transformaron en un proyecto de "reconciliación" y, posteriormente, en un museo para la transmisión de la experiencia y la memoria. En Carabanchel, en cambio, desde un principio la demanda para la conservación de la cárcel apunta al reconocimiento público e impugna la bandera de la memoria histórica. Sin embargo, esta demanda, que no logra encontrar un camino hacia la institucionalización, acaba derivando, entre otras cosas, en una querella judicial contra la impunidad de los crímenes del franquismo, que se pone en marcha casi cuarenta años después del fin de la dictadura ${ }^{35}$.

${ }^{34}$ Otro ejemplo fue el arresto internacional de Pinochet, que ya mencionamos. En ese caso, el proceso fue puesto en marcha por la justicia española, que pidió su extradición invocando el derecho humanitario. La coyuntura de la detención de Pinochet en Londres -aunque no se lograra su extradición a España- tuvo según algunos observadores un efecto "transfert" en la sociedad española, que apoyó y siguió el procesamiento del dictador chileno como si fuese su propio dictador, que nunca había sido procesado (Martín Cabrera 2011: 199-200).

35 Paradójicamente, para desestimar los requerimientos derivados de esta querella, distintas instancias del Estado español han esgrimido la misma Ley de Amnistía que los presos de Carabanchel invocaban hace cuarenta años. 




FIG. 10.- Momento de la manifestación conmemorativa del derribo de la Cárcel de Carabanchel, octubre 2014. Algunos manifestantes frente al antiguo hospital penitenciario, hoy Centro de Internamiento de Extranjeros. Fuente: Jesús Rodríguez, SOS Carabanchel.

Otro elemento de comparación con el proceso de Villa Grimaldi tiene que ver con las manifestaciones y las performances que ocupan periódicamente el solar desierto de la cárcel. Como hemos visto, aquí también las manifestaciones funcionan como un elemento de aglutinación y son herramientas para la transmisión de memorias y la construcción de identidades. Al igual que en Villa Grimaldi, la memoria que se comparte y se transmite en estas manifestaciones también ha ido evolucionando, y muestra —entre otras cosas - que el concepto de "víctimas" puede ensancharse y que la conmemoración puede derivar en demandas de otros tipos. Los relatos de las visitas guiadas que realizan periódicamente los vecinos han ido incorporando nuevos elementos en los últimos años. Entre ellos, por ejemplo, un monumento ubicado en una plaza aledaña al predio, y dedicado a la memoria de una vecina, militante de izquierda y dirigente estudiantil, asesinada en 1980 por un grupo de extrema derecha $^{36}$. Se trata en este caso de una víctima de la violencia política en la transición, cuyo recuerdo, sin embargo, aparece en el recorrido dedicado a la Cárcel.

${ }^{36}$ Se trata de un monumento no-institucional, que re-utiliza la estatua decorativa de una joven mujer que se ubica en la plaza de Aluche. A los pies de esa estatua se instaló una placa en 2013, en memoria de la joven asesinada y de "todos los asesinados por el fascismo". En 2015 la Junta municipal del distrito ha oficializado el homenaje dando su nombre a unos jardines cercanos a la plaza. 
También las manifestaciones del aniversario del derribo indican evoluciones en el concepto de "Víctima" y en los objetivos de la comunidad reunida en torno a la conservación de Carabanchel. El único edificio del complejo carcelario que sobrevivió a la demolición es una estructura que había sido construida en los años sesenta para servir como hospital penitenciario, adyacente al panóptico original. Este edificio en 2005 fue restaurado y "reciclado" como Centro de Internamiento de Extranjeros (CIE), es decir, un nuevo tipo de cárcel. Después del derribo del panóptico, en estos últimos años, el movimiento surgido en torno a la conservación de la Cárcel converge con la demanda ciudadana por el cierre de este Centro de Internamiento y la defensa de los derechos de los detenidos "sin papeles". El objetivo es ahora la transformación del CIE en un centro por la paz y la memoria

De manera parecida al Via Crucis de Villa Grimaldi, la manifestación conmemorativa del derribo que se realizó en octubre de 2014 incluyó una performance que agregaba ambas demandas. En este caso, el traslado de las víctimas del pasado a las del presente se realiza por el común denominador de la represión. Se organizó una procesión que repetía el camino de los presos políticos que construyeron la Cárcel a principios de los años cuarenta: desde el ex centro de detención y hoy convento y colegio de Santa Rita — que es otro lugar que se incorpora en ocasiones a las visitas de Carabanchel - el cortejo llegó hasta el solar y la entrada del CIE. La marcha iba liderada por una fila doble de individuos que, emulando a los presos de entonces, estaban atadas con cuerdas, y llevaban carteles que indicaban: "preso del franquismo" o "preso por no tener papeles". Representantes de estos dos tipos de presos avanzaron tomados de la mano hasta la entrada del Centro de Internamiento, como una procesión de víctimas heterogéneas, unidas por una demanda trans-temporal de justicia (Fig. 10).

\section{REFLEXIONES CONCLUSIVAS}

El significado patrimonial de Villa Grimaldi y de la Cárcel de Carabanchel nace de las necesidades de quienes los observan y usan. Estos sitios cobran valor por su condición de documentos -evidencias materiales o pruebas de lo que pasó-, y por esto sus vestigios pueden ser objeto de un interés arqueológico y de demandas de conservación. También son monumentos del pasado, símbolos de reconocimiento público que vehiculan una pedagogía de la historia. Y, finalmente, son memoriales, cuya función es transmitir la experiencia y el recuerdo. Estos distintos valores funcionales —documental, memorial, monumental - se asocian con estos sitios y los convierten en objetos de una demanda de "rescate", conservación o exhibición. La preeminencia de una de estas funciones sobre las otras, o la evolución de las demandas ciudadanas desde uno a otro ámbito, dependen de la relación que la sociedad establece con la verdad, la memoria y la justicia en lo relativo a los crímenes de las dictaduras. El equilibrio, la tensión o la mezcla de estos elementos dependen de muchos factores históricos y culturales, que diferencian los procesos de los lugares que aquí hemos estudiado.

El valor de estos sitios nace de las comunidades de memoria que convergen alrededor de ellos, y que reivindican al Estado su conservación. Tanto en Villa Grimaldi 
como en la Cárcel de Carabanchel el patrimonio de la represión es un punto territorial "sensible", en torno al cual se produce agregación y organización ciudadana, y en el cual se realiza la ocupación física y la reivindicación del espacio público por iniciativa de individuos y grupos no institucionales. Las manifestaciones, los rituales colectivos y las performances son ocasiones para la expresión pública de estas comunidades, y un elemento principal para la difusión y transmisión de estos patrimonios. En ambos lugares, a pesar o más allá de la construcción de monumentos, estos rituales actúan como una embodied memory que se transmite por la oralidad, la presencia y los gestos (Taylor 2003). A través de su repetición y continuidad en el tiempo, estos rituales no sólo favorecen la presencia y la legitimación de colectivos ciudadanos en el espacio público, sino que permiten que sus discursos se mantengan, se difundan y evolucionen. Las performances otorgan a estos sitios un significado múltiple y cambiante, y constituyen un elemento fundamental en la construcción social de su valor, que no sólo se expresa a través de un lenguaje arquitectónico, sino también oral y teatral. El análisis de estos rituales ofrece una clave para entender la dimensión viva de estos patrimonios, y su especificidad en cada contexto territorial y cultural.

Los intelectuales y las redes académicas no se limitan a un papel observador de estos procesos, sino que pueden tener un rol relevante en el nacimiento y desarrollo de los movimientos ciudadanos que surgen entorno a estos patrimonios: pueden ser mensajeros de nuevos criterios o lenguajes, o "poner palabras" y ofrecer herramientas a los procesos de cambio cultural en que se inserta la vida de estos vestigios. A su vez, las interrelaciones entre los actores que convergen en estos sitios - vecinos, víctimas, intelectuales, activistas - se despliegan en un milieu de memoire, un medio de memoria, que también es vehiculado por lenguajes y redes internacionales —académicas, jurídica y sociales- que constituyen el marco en que nace y evoluciona el valor patrimonial de estos sitios.

Este "marco" de la memoria, si por un lado otorga sentido y legitimidad pública a actores y discursos no institucionales, por otro lado contribuye a seleccionar los objetos y los sujetos de la memoria que estos lugares pretenden vehicular. Tanto en Villa Grimaldi como en Carabanchel el "universo de víctimas" sobre el que se construye el valor del vestigio nace de algunas selecciones fundamentales, que otorgan legitimidad a algunas víctimas y a algunas memorias, excluyendo o invisibilizando otras. Sin embargo, estas selecciones de la memoria no necesariamente son estáticas. En las evoluciones físicas y "performativas" de ambos lugares se ven ejemplos de cómo este universo puede ampliarse a otros sujetos conforme cambia el clima cultural en el que viven estos patrimonios. A la vez, las conmemoraciones que se desarrollan en ambos sitios establecen vínculos entre víctimas de distintos tiempos y distintos tipos de injusticia, y entre el recuerdo de las violencias del pasado y la denuncia de situaciones del presente.

La institucionalización de estos patrimonios por parte de los Estados es un tema clave, que influye en sus lenguajes, transformaciones y visibilidad. Las demandas ciudadanas sobre el patrimonio se desarrollan en una dinámica de relación con las autoridades. Las políticas institucionales han podido adoptar y, en cierta medida, desvirtuar las demandas locales sobre estos patrimonios en nombre de la reconciliación o el consenso social, como muestran las reflexiones sobre Villa Grimaldi. 
O las han denigrado y frustrado, como en Carabanchel. La diferencia fundamental entre ambos casos tiene que ver con la existencia de políticas estatales de memoria que legitimen el valor patrimonial de estos sitios: mientras en Chile a lo largo de la transición a la democracia se ha desarrollado una memoria institucional sobre los crímenes de la dictadura por parte del Estado, centrada en los conceptos, aún contradictorios, de "derechos humanos" y "reparación simbólica"; en el caso español, el Estado no ha formulado una política pública de este tipo, y aun cuando ha querido hacerlo, las decisiones institucionales en éste ámbito han estado sujetas a los cambios de los gobierno y a sus acuerdos políticos. Por esto la Cárcel de Carabanchel ha sido demolida.

El estado chileno, a diferencia del español, implementa políticas de estado que establecen verdades públicas sobre la represión dictatorial. Por esto, pueden existir conmemoraciones de Estado, memoriales y museos de la memoria institucionales, más allá de la pertenencia partidista de los gobiernos. En el caso de España, las iniciativas institucionales hacia el pasado han dependido básicamente de la voluntad de las autoridades regionales y de sus partidos de referencia. Aquí, los patrimonios de la represión no son algo consensuado a nivel estatal, sino más bien, cobran sentido en el marco de la constelación simbólica de los distintos nacionalismos e identidades partidistas.

Desde el punto de vista de las políticas de Estado, Villa Grimaldi y la Cárcel de Carabanchel ejemplifican dos distintas estrategias institucionales para la superación de un conflicto sobre el pasado: por un lado, la construcción problemática de un discurso de consenso, por el otro, un silencio obstinado.

\section{BIBLIOGRAFÍA CITADA}

Aguilar, Mario. 2005. "The ethnography of the Villa Grimaldi in Pinochet's Chile: from public landscape to secret detention center". Iberoamericana 18: 7-23.

Ashworth, Gregory y Tunbridge, John E. 1996. Dissonant Heritage: The Management of the Past as a Resource in Conflicts. Chichester and Nueva York: John Wiley \& Sons.

Assman, Aleida. 2002 (1999). Ricordare. Forme e mutamenti della memoria culturale. Bolonia: Il Mulino (ed. or., Munich, 1999).

Baer, Alejandro. 2010. "La memoria social: breve guía para perplejos", en Zamora, José Antonio y Sucasas Alberto. (Eds.), Memoria - Política - Justicia. En diálogo con Reyes Mate 131-148. Madrid: Editorial Trotta.

Brunner, José Joaquín. 1990. "Chile: claves de una transición pactada". Nueva Sociedad 106: 6-12 http:/ /www.socialismo-chileno.org/apsjb/1990/brunner_90.pdf

Comisión Nacional sobre Prisión Política y Tortura. 2004. Informe de la Comisión Nacional sobre Prisión Política y Tortura. http://www.bcn.cl/bibliodigital/dhisto/lfs/Informe.pdf

Comisión por la Verdad y la Reconciliación 1996 (1991). Informe de la Comisión por la Verdad y la Reconciliación, Gobierno de Chile: http://www.ddhh.gov.cl/ddhh_rettig.html

Cuesta, Josefina. 2008. La odisea de la memoria. Historia de la memoria en España siglo XX. Madrid: Alianza.

Ferrándiz, Francisco. 2014. El pasado bajo tierra. Exhumaciones contemporáneas de la Guerra Civil. Madrid: Anthropos.

Filippucci, Paola. 2009. "Heritage and methodology. A view from social anthropology", en Carman, John y Stig Sorensen, Marie Louise. Heritage studies: methods and approaches: 319-325. Nueva York: Routledge. 
Garcés, Mario y Nicholls, Nancy. 2005. Para una historia de los derechos bumanos en Chile. Historia institucional de la Fundación de Ayuda Social de las Iglesias Cristianas (FASIC) 1975-1991, Santiago: LOM.

García García, Sergio. 2013. "Cuando éramos malos...." El estigma penitenciario en Carabanchel", en Ortiz, Carmen (ed.), Lugares de represión, paisajes de la memoria. La cárcel de Carabanchel: 141161. Madrid: Catarata.

Giblin, John D. 2013. "Post-conflict heritage: symbolic healing and cultural renewal", International Journal of Heritage Studies. (2013), DOI: 10.1080/13527258.2013.772912

González-Ruibal, Alfredo y Falquina, Alvaro. 2013. "La cárcel de Carabanchel: una aproximación arqueológica", en Ortiz, Carmen (ed.), Lugares de represión, paisajes de la memoria. La cárcel de Carabanchel 100-121. Madrid: Catarata

Halbwachs, Maurice. 2004 [1968]. Los marcos sociales de la memoria. Zaragoza: Prensas Universitarias de Zaragoza.

Hartog, François. 2007. Regímenes de historicidad: presentismo y experiencia del tiempo. México DF: Universidad Iberoamericana.

Huyssen, Andreas. 2001. En busca del futuro perdido. Cultura y memoria en tiempos de globalización. Buenos Aires: FCE.

Iniesta, Monserrat. 2009. "Patrimonio, ágora, ciudadanía. Lugares para negociar memorias productivas", en Vinyes, Ricard. El estado y la memoria. Gobiernos y ciudadanos frente a los traumas de la historia: 467-495. Barcelona: RDA.

Isnenghi, Mario (ed.). 1996. I luoghi della memoria. Simboli e mitidell'Italia unita. Roma-Bari: Laterza. Jedlowsky, Paolo. 1994. Il sapere dell'esperienza. Milán: Il Saggiatore.

Jelin, Elizabeth. 2013. "Memoria y democracia: una relación incierta". Revista de Ciencia Política de la Universidad de Chile 51-2: 129-144.

Jelin, Elizabeth y Victoria Langland (ed.). 2003. Monumentos, memoriales y marcas territoriales. Madrid y Buenos Aires: Siglo XXI.

Lazzara, Michael. 2007. Prismas de la memoria: narración y trauma en la transición chilena. Santiago: Cuarto Propio.

Logan, William and Keir Reeves (eds). 2009. Places of Pain and Shame. Dealing with Difficult Heritage. Nueva York: Routledge.

Lopez, Loreto. 2010. "De centros de detención a lugares de memoria", Archivo Londres 38: http:// www.londres38.cl/1934/w3-article-88243.html

Lorenzo Rubio, César. 2013. Cárceles en llamas. El movimiento de presos sociales en la transición. Madrid: Virus.

MacDonald, Sharon. 2009. Difficult Heritage: Negotiating the Nazi Past in Nuremberg and Beyond. Nueva York: Routledge.

Martin Cabrera, Luis. 2011. Radical justice. Spain and Southern Cone beyond market and the State. Plymouth, UK: Bucknell University Press.

Meskell, Lynn. 2002, "Negative Heritage and Past Mastering in Archaeology". Anthropological Quarterly 75: $557-574$.

Moulian, Tomás. 1997. Chile actual: anatomía de un mito. Santiago: LOM.

Nora, Pierre. 1984. "Entre mémoire et histoire. La problematique des lieux", en Nora, Pierre (ed.), Les lieux de mémoire, vol.1, La Republique: XVIII-XLII. Paris: Gallimard.

Nora, Pierre. 1992. "L'ère de la commémoration", en Nora, Pierre (dir.), Les lieux de mémoire, vol. 3, Les Frances: 975-1012. Paris: Gallimard.

Ortiz, Carmen. 2013. "Patrimonio sin monumentos. Políticas de memoria y gestión patrimonial de los sitios de represión del franquismo. El caso de la Cárcel de Carabanchel", en Ortiz, Carmen (ed.), Lugares de represión, paisajes de la memoria. La cárcel de Carabanchel, Madrid: Catarata.

Portales, Felipe. 2000. Chile: una democracia tutelada. Santiago: Sudamericana.

Prats, Llorenç. 1997. Antropología y patrimonio. Barcelona: Ariel.

Rebolledo, Javier. 2012. La danza de los cuervos. El destino final de los desaparecidos. Santiago: Ceibo.

Richard, Nelly. 2001. "Sitios de la memoria: vaciamiento del recuerdo". Revista de Crítica Cultural 23: $231-271$. 
Sánchez Carretero, Cristina. 2013. "Patrimonialización de espacios represivos. En torno a la gestión de los patrimonios incómodos en España", en Ortiz, Carmen (ed.), Lugares de represión, paisajes de la memoria. La cárcel de Carabanchel: 28-41. Madrid: Catarata.

Serrano, Rodolfo y Serrano, Daniel. 2003. Toda España era una cárcel. Memoria de los presos del franquismo. Madrid: Punto de Lectura.

Taylor, Diana. 2003. The Archive and the Repertoire. Performing Cultural Memory in the Americas. Durham: Duke Univerity Press.

Taylor, Diana. 2010. “Trauma, memoria y performance: un recorrido en Villa Grimaldi con Pedro Matta", E-misférica, 7.2: http://hemisphericinstitute.org/hemi/en/e-misferica-72/taylor

Uzzel, David y Ballantyne, Roy. 2008 [1999]. "Heritage that hurts. Interpretation in a post modern world", en Fairclough, Graham, Harrison; Rodney; Jameson, John y Scofield, John. (eds), The Heritage Reader: 502-513. Londres: Routledge.

Valverde, Clara. 2013. Desenterrar las palabras. Transmisión generacional del trauma de la violencia politica del siglo XX en el Estado español. Madrid: Icaria.

Viejo Rose, Dacia. 2013. "Patrimonio cultural armado: la violencia cultural y simbólica” en Ortiz, Carmen. (ed), Lugares de represión, paisajes de la memoria: Madrid: 21-27. Catarata.

Viejo Rose, Dacia. 2014. Reconstructing Spain. Cultural Heritage and Memory after Civil War. Brigthon: Sussex Academic Press.

Violi, Patricia. 2011. "E' successo propio qui". Gli ambienti come testimoni. Analisi del caso cileno". Lexia. Rivista di semiotica 9-10: 95-132.

Wilde, Alexander. 1999. "Irruptions of Memory: Expressive Politics in Chile's Transition to Democracy". Journal of Latin American Studies 31-2: 473-500.

Winter, Ulrich (ed.). 2006. Lugares de memoria de la Guerra Civil y el franquismo. Representaciones literarias y visuales. Madrid-Frankfurt: Iberoamericana.

Fecha de recepción: 17 de abril de 2015

Fecha de aprobación: 22 de junio de 2015 